\title{
An analysis of Landsat 7 and Landsat 8 underflight data and the implications for time series investigations
}

\author{
Christopher E. Holden ${ }^{\mathrm{a}, *}$, Curtis E. Woodcock ${ }^{\mathrm{a}}$ \\ ${ }^{a}$ Center for Remote Sensing, Department of Earth and Environment, Boston University, \\ 685 Commonwealth Avenue, Boston, MA 02215, United States
}

\begin{abstract}
The newly launched Landsat 8 satellite continues the long and extremely important record of Earth observation from the Landsat program. We analyzed differences between Landsat 7 and Landsat 8 surface reflectance and cirrus cloud characterization to address how substitutable Landsat 8 observations are within this long archive. Comparison of surface reflectance estimates acquired near simultaneously during Landsat 8's underflight orbital placement shows that Landsat 8 surface reflectance is consistently darker in the blue, green, and red bands and brighter in the near infrared than in Landsat 7 . Vegetation indices that rely on the visible and near infrared bands should be used with caution as individual biases in index components can be amplified to create large biases in vegetation indices. We also analyzed time series datasets from the Landsat Climate Data Record (CDR) surface reflectance product across four scenes that contained only Landsat 7 data, Landsat 7 data and only Landsat 8 data post-launch, and Landsat 7 data and data from both sensors post-launch to investigate how sensor differences propagate in time series analysis. If left uncorrected or unexplained, the difference in reflectance between Landsat 7 and Landsat 8 creates spurious time trends in visible wavelengths and in the Normalized Difference Vegetation Index (NDVI). The introduction of Landsat 8 into time series of Landsat 7 data also biases the mean reflectance or vegeta-
\end{abstract}

\footnotetext{
* Corresponding author

Email address: ceholden@bu.edu (Christopher E. Holden)
}

Preprint submitted to Remote Sensing of Environment

February 2, 2016

(C) 2016. This manuscript version is made available under the Elsevier user license http://www.elsevier.com/open-access/userlicense/1.0/ 
tion index value as measured by a time series model intercept while increasing the Root Mean Squared Error of such models. We characterized the spectral reflectance of cirrus clouds in the underflight data that were omitted from Landsat 7 cloud masks but were detected in Landsat 8's cloud mask due to the use of the newly added cirrus band. While these cirrus cloud observations missed in Landsat 7's cloud mask are only slightly brighter in the visible bands, a simulation of time series containing Landsat 8 data that does not use the cirrus band shows that omission of cirrus clouds can result in anomalously brighter time series intercepts and positive time trends. Our results indicate that while Landsat 8 has improved on the legacy of previous sensors through increased radiometric resolution, better cloud identification, and better geometric accuracy, difference in reflectance between sensors in the current Landsat CDR product must be corrected or explained within time series analysis to avoid deleterious consequences. Future efforts should identify the contributions of target specific effects versus differences in atmospheric correction methods to better inform approaches to synthesize the two sensors.

Keywords: Landsat 8; time series; change detection; CCDC; cirrus clouds;

\section{1. Introduction}

The Landsat program, spanning over 40 years, provides the longest and most 3 informative satellite record of our changing planet (Loveland and Dwyer, 2012

4 Roy et al. 2014). After spending most of its lifespan operating with a pay for 5 access model, the Landsat archive was finally made freely available in 2008 and 6 methods that take advantage of this data policy quickly proliferated (Wulder 7 et al. 2012). These methods that work on time series of Landsat data have 8 been used extensively to map forest cover change (Kennedy et al., 2007, Asner 9 et al. 2009; Kennedy et al., 2010, Huang et al., 2010; Vogelmann et al., 2012,

10 Zhu et al., 2012, Verbesselt et al., 2012, Zhu and Woodcock, 2014, Brooks et al.

112014 ; Hansen et al. 2014), including a study that mapped global forest cover 12 change between 2000 and 2012 at Landsat's $30 \mathrm{~m}$ resolution (Hansen et al. 
2013). This critical information on the magnitude and spatial patterns of forest change has also been extended to 1990 using Landsat data (Kim et al., 2014). While many recent Landsat time series applications have focused on identification of forest cover change, some methods have attempted to identify changes in all land covers (Zhu and Woodcock, 2014) or classify specific agricultural crops (Yan and Roy, 2014). Landsat time series also provide unique traits suitable for synthesis with lidar data for estimation of forest biomass as disturbance information from Landsat MSS through ETM+ have improved estimates of forest biomass (Pflugmacher et al. 2012$)$. Consistent and continuous Landsat observations enable the transition from static snapshots of ecosystem properties to characterization of processes and dynamics of interest to ecologists Kennedy et al., 2014), including phenology (Melaas et al., 2013) and insect infestations (Meigs et al., 2011). Refined information about dynamics within human systems is now also a target for Landsat based research because Landsat's long time record, locally relevant spatial scale (Hansen et al., 2013), and recent advances in mapping frequency enables the analysis of change in land cover within the context of socioeconomic or policy drivers. Such efforts include the monitoring of forest cover change to address policy questions in regions (Kennedy et al. 2012 Griffiths et al., 2012) or nationally using wall to wall maps (Hansen et al. 2014) and within a sampling framework (Masek et al., 2013), and comparing rates of urbanization across rapidly growing cities (Schneider, 2012).

Technological advances since the development of Landsat 7 and the move from a whiskbroom to a pushbroom style sensor have greatly increased the measurement accuracy of Landsat 8 data. The signal to noise ratio (SNR) on Landsat 8's OLI is much higher than the mission specifications and an order of magnitude higher than the SNR on Landsat 7 (Knight and Kvaran, 2014 Morfitt et al. 2015) while the increase to 12-bit radiometric resolution extends the range of measurable radiances and reduces pixel saturation (Morfitt et al. 2015). The geometric accuracy on Landsat 8 is astounding and meets or exceeds all mission requirements (Storey et al., 2014). The absolute geolocation accuracy of Landsat 8 , in particular, improves so much on the mission specifications 
that it will be used to improve the geometric accuracy of the entire Landsat archive by improving ground control points in the Global Land Survey (GLS) network. Improvements to onboard storage and ground transmission capacity enable Landsat 8 to acquire $60 \%$ more image scenes per day than Landsat 7 as of 2014 (Roy et al. 2014) and approximately 725 scenes are currently acquired per day. This increased image acquisition frequency will help further reduce differences in image availability due to geographic variation in observation conditions and ground receiving station access (Kovalskyy and Roy, 2013). Landsat 8 continues the legacy of the Landsat program by providing much higher quality and quantity Earth observations vital to time series investigations.

Designed to continue this legacy, the spectral band specifications for Landsat 8's Operational Land Imager (OLI) sensor are, for the most part, very similar to previous sensors (see Table .1p. Several spectral bands have been narrowed slightly to provide more precise measurements that are less correlated with other bands. The near infrared band on Landsat 8 (OLI Band 5) changed the most compared to other bands as it was narrowed substantially from $0.77 \mu \mathrm{m}$ to $0.90 \mu \mathrm{m}$ on ETM+ to $0.85 \mu \mathrm{m}$ to $0.88 \mu \mathrm{m}$ specifically to avoid an atmospheric water absorption feature at $0.85 \mu \mathrm{m}$. As such, we might expect near infrared measurements from Landsat 8 to be brighter than from previous Landsat sensors. The first shortwave infrared band (ETM+ band 5 and OLI band 6) also narrowed significantly and the second shortwave infrared band (ETM+ band 7 and OLI band 7), while it did not change as much, now excludes wavelengths $(>2.3 \mu \mathrm{m})$ with the strongest spectral response function in ETM+ band 7 (Flood, 2014).

The changes in spectral bandpasses are an improvement over previous sensors, but one that may affect the comparability with previous sensors. Li et al. (2014) analyzed Landsat 7 and Landsat 8 surface reflectance and vegetation indices in four land cover types. They found differences in spectral bands between the two sensors that contributed to further differences in vegetation indices, especially when using indices calculated using the visible bands. Zhu et al. (2015a) analyzed land cover change and dynamics within the rapidly urbanizing city of 
Ghuangzhou, China and found the NDVI to be positively biased when adding Landsat 8 into time series of Landsat 4, 5, and 7. Flood (2014) used 793 cloud free 8-day pairs of images over 123 Landsat scenes in Australia to assess the difference between Landsat 8 and Landsat 7 top of atmosphere (TOA) and surface reflectance, including how the differences propagate in biophysical models. Differences in TOA reflectance were close to $1 \%$ for all bands except the near infrared and second shortwave infrared which were brighter by $6 \%$ and $3 \%$, respectively. Surface reflectance correction using the methods of Flood et al. (2013) reduced these differences to within 1 to $2 \%$ for all bands except the blue band (ETM+ band 1 and OLI band 2). Unadjusted surface reflectance inputs to a fractional cover model created biased estimates relative to Landsat 7 with bare cover underestimated by $5 \%$ and vegetated cover overestimated by $7 \%$. The differences in surface reflectance estimates were systematic and adjustable using a simple linear regression. Landsat 8 adjusted surface reflectance values produced fractional cover estimates equal to estimates from Landsat 7 . Flood (2014), however, also noted that there was some variance across the 123 scenes in the relationship between Landsat 7 and Landsat 8 surface reflectances and that the corrections performed are not likely to be extendable beyond the study area. Mishra et al. (2014) used Landsat 7 and Landsat 8 data in combination with simultaneous or near simultaneous EO-1 Hyperion acquisitions to assess differences in cross-sensor calibration. EO-1 Hyperion was used to develop Spectral Band Adjustment Factors (SBAF) that corrected for the measurement differences due to different spectral bandpasses. Once the SBAF were applied to Landsat 8 data, TOA reflectance differences in a near simultaneously acquired Landsat 7 and Landsat 8 image pair were less than $2 \%$ for all analogous bands except for a $4 \%$ difference in the near infrared.

Landsat 8 includes a new band in the mid-infrared centered on $1.375 \mu \mathrm{m}$ that is designed specifically to find cirrus clouds in Landsat OLI imagery (Loveland and Dwyer, 2012, Irons et al., 2012, Roy et al., 2014). Successfully used on the Moderate Resolution Imaging Spectrometer (MODIS) instrument, this band significantly improves upon alternative methods of detecting cirrus clouds 
by at least an order of magnitude (Gao and Kaufman, 1995). Without such a tool, cirrus cloud detection in historical Landsat imagery was significantly more difficult. For example, an analysis of all Landsat images acquired during the first year over the conterminous United States found that $7 \%$ of the data were identified as low confidence cloud but high confidence cirrus clouds, suggesting that $7 \%$ of historic Landsat data may be contaminated with cirrus clouds (Kovalskyy and Roy, 2015). While the percent of undetected cirrus clouds may vary across the globe, this result highlights another difference between Landsat 8 and previous sensors that may be important when combining datasets.

\subsection{Objectives}

As previous studies have indicated (Li et al., 2014, Flood, 2014, Mishra et al. 2014), the change in Landsat 8's spectral bandpasses create differences in radiance and reflectance measurements relative to Landsat 7 . While these studies have provided excellent evidence on the differences between sensor, they have not assessed sensor-specific differences in the Landsat Climate Data Record (CDR) community product. The Landsat CDR product is designed to improve on the Level 1 Product usability by providing atmospherically corrected Landsat data and uses different algorithms for Landsat TM/ETM+ and Landsat OLI data. Because any potential differences in the correction algorithms might enhance target specific differences due to spectral bandpasses, it is important to assess the relative consistency of the CDR products across sensors. Finally, it is still unclear how differences between Landsat 8 and previous sensors are manifested in time series analyses.

To assess the potential differences between Landsat 7 and Landsat 8 characteristics in the Landsat CDR product, we posed the following questions:

1. Do Landsat 7 and Landsat 8 spectral reflectances from CDR differ significantly? If so, what is the nature of the differences?

2. Are time series of Landsat 7 and Landsat 8 data different? What is the effect of combining data from the two sensors? 
3. What are the spectral characteristics of cloud and cirrus clouds masked by Landsat 8 but omitted in Landsat 7 data?

4. Are the cloud masking improvements in Landsat 8 apparent in time series?

\section{Datasets}

Atmospheric correction of Landsat 7 and Landsat 8 data within the Landsat CDR is performed using two different algorithms driven by different input ancillary data. Landsat 7 data are corrected using the Landsat Ecosystem Disturbance Adaptive Processing System (LEDAPS) algorithm (Masek et al., 2006) while Landsat 8 data are corrected using "L8SR", a newly developed algorithm that takes advantage of some of Landsat 8's new sensor characteristics (U.S. Geological Survey, 2015; Vermote, 2016). The LEDAPS algorithm retrieves surface pressure, water vapor, and air temperature inputs from the NOAA National Centers for Environmental Protection (NCEP) reanalysis dataset while L8SR calculates surface pressure based on the target's elevation and uses the Moderate Resolution Imaging Spectroradiometer (MODIS) Climate Modeling Grid - Aerosol (CMA) product for water vapor and air temperature estimates. Ozone data are retrieved from the Ozone Monitoring Instrument (OMI) or Total Ozone Mapping Spectrometer (TOMS) for LEDAPS and from the MODIS Climate Modeling Grid (CMG) coarse resolution ozone product in L8SR. Aerosol Optical Thickness (AOT) is estimated in LEDAPS using the dark, dense vegetation (DDV) method (Kaufman et al., 1997) while L8SR uses the MODIS CMA product. LEDAPS uses view zenith angle geometry from the image metadata while L8SR hard codes this angle to 0 degrees. These differences in ancillary data may be another cause for potential disagreement in the surface reflectance estimates, but diagnosing the effect of different ancillary information on the output reflectance estimates is outside of the scope of this effort.

The L8SR data products are currently considered "provisional" because the algorithm, the implementation of the algorithm in software, and the subsequent output products have not been completely validated U.S. Geological Survey, 
2015). The algorithm implementation has been corrected to fix artifacts near coastal land and water boundaries, but visual artifacts remain among cloud edges and areas of high topographic variation in some images. The correction of these artifacts should not significantly alter the findings of this work that is based on the analysis of millions of pixels across many scenes. We refer the reader to the product changelog in the Landsat $8 \mathrm{CDR}$ product guide (U.S. Geological Survey, 2015) to monitor changes to the product. In addition, the L8SR algorithm has a few caveats: the algorithm is not run on scenes with a solar zenith angle greater than 76 degrees and surface reflectance retrievals may be uncertain in hyper-arid, snow-covered, coastal regions with small amounts of land relative to water, or high cloud cover environments (U.S. Geological Survey, 2015).

We used two datasets to address the questions posed about the continuity of surface reflectance observations from Landsat 7 to Landsat 8: Landsat "underflight" data that provides near simultaneous observations from both sensors, and time series of Landsat data covering seven years of Landsat 7 and two years of Landsat 8 .

\subsection{Landsat 8 Underflight}

On March 29-30, 2013, prior to the establishment of its final orbit, Landsat 8 flew in "underflight" mode in position with Landsat 7 allowing for almost simultaneous image acquisitions. The scene centers for Landsat 8 did not exactly match with Landsat 7 because it had not reached its operational Worldwide Reference System (WRS-2) orbit, but the images acquired provided substantial overlap for comparison. The time delay between the scene center acquisition for Landsat 7 and Landsat 8 was usually between two to five minutes (see Table .2 .

The underflight Landsat 8 data were preprocessed to a Level 1 Terrain corrected (L1T) product and processed to surface reflectance using the L8SR algorithm by the USGS EROS Data Center. The data were processed and made available to the Landsat Science Team by the USGS, but can now be downloaded 
and analyzed as part of the "Pre-WRS-2" Landsat archive (the Landsat Scene Identifier for each image is available in Table .2. Cloud, cloud shadow, and snow masks were also provided for Landsat 8 data using CFmask, a C implementation of the Fmask algorithm (Zhu and Woodcock, 2012; Zhu et al., 2015b). Two CFmask images were generated for each Landsat 8 image: a mask that incorporated information from the new cirrus band on Landsat 8, and a mask that ignored the cirrus band and used the same algorithm as Fmask uses for Landsat TM/ETM+ data. The CFmask output used in this evaluation differed from the standard product because the cloud masks that used the cirrus band identified cirrus clouds separate from other types of clouds. Landsat 7 data corresponding to each Landsat 8 underflight acquisition were acquired for comparison. The Landsat 7 data were preprocessed to L1T products and atmospherically corrected using the Landsat Ecosystem Disturbance Adaptive Processing System (LEDAPS) algorithm (Masek et al. 2006). Cloud, cloud shadow, and snow masks were also generated for each Landsat 7 image using CFmask. We created layer stacked images containing corresponding image bands for each matching pair of Landsat 7 and Landsat 8 images. The new shorter wavelength blue band and the cirrus band on Landsat 8 were excluded as they had no direct comparison with the Landsat 7 data. To avoid confusion relating to the band numbering change between Landsat 7 and Landsat 8, we refer to spectral bands on ETM+ and OLI using by the common name of the spectral range they measure. Refer to Table 1 for the pairing between the spectral wavelength names, the sensor band numbering, and the spectral wavelengths measured.

\subsection{Landsat time series}

We acquired all available Level 1 Terrain corrected (L1T) Landsat ETM+ and OLI images with less than 20\% cloud cover between 2008 and 2015 for Worldwide Reference System (WRS-2) path/rows 16/41, 23/37, 34/32, and 43/34 as Landsat CDR products. According to the 2011 National Land Cover Database (NLCD) (Homer et al., 2015), the land cover in scene in Florida, United States (P016R041) is primarily comprised of natural or cultivated herba- 
ceous $(36 \%)$, wetlands $(30 \%)$, and developed $(12 \%)$ categories. The scene in Mississippi, United States (P023R037) is marked by cultivated herbaceous (53\%), wetlands (17\%), and forest cover (16\%). Our site in Colorado, United States (P034R032) intersects the Rocky Mountains and the Denver urban area and primarily contains forest (40\%), natural and cultivated herbaceous (26\%), and shrub (21\%) covers. Finally, the site in California, United States (P043R034) is centered on the Central Valley and is covered by natural or cultivated herbaceous vegetation $(57 \%)$, forest $(18 \%)$, and shrub $(13 \%)$ cover.

Landsat images were atmospherically corrected using LEDAPS (Masek et al. 2006 ) for ETM+ data and L8SR for OLI data (U.S. Geological Survey, 2015). Atmospheric correction within the Landsat CDR product was performed by the USGS EROS Science Processing Architecture (ESPA) (LEDAPS version "LEDAPS_2.2.1" and L8SR version "18_surface_reflectance_0.2.0") (Loveland and Dwyer, 2012). We transformed the surface reflectance values into the NDVI, EVI, NBR, and NDMI spectral indices. Thermal band data were converted into top of atmosphere brightness temperature.

Clouds, cloud shadows, and snow were identified using the Fmask algorithm (Zhu and Woodcock, 2012; Zhu et al., 2015b) with a cloud probability threshold of 12.5 and cloud, cloud shadow, and snow mask dilation of 5 pixels. The cloud probability threshold and mask dilation parameters were chosen to provide a conservative cloud mask result intended to limit omission of clouds. Errors of commission in cloud masks are less harmful than errors of omission in time series with hundreds of available images, so we used a custom run of Fmask instead of the available CFmask product. We also generated an additional Fmask image for Landsat 8 imagery using the same parameters that did not use information from the new cirrus band (as in Zhu et al. (2015b)) to assess the difference in noise reduction associated with having a band specifically designed to aid cloud detection.

Images within each path/row were layer stacked and aligned to a uniform image extent for further analysis. We excluded the new blue and cirrus spectral bands measured by Landsat 8 and only used one thermal band (Band 10) in 
Landsat 8 to facilitate comparison with Landsat 7 . The number of total images available in each scene location varied between 164 and 183 with Landsat 8 contributing between 36 and 39 images (see Table .3.

\section{Methods}

\subsection{Landsat 8 Underflight}

\subsubsection{Spectral comparison}

Clouds, cloud shadows, and snow in the Landsat 7 and Landsat 8 image pairs were masked from analysis using the CFmask band. The clouds and cloud shadows shifted position and shape considerably during the short time interval between the acquisitions by Landsat 7 and Landsat 8 (see Supplementary Figure 1). Because no solution exists to mask every cloud in a remote sensing image, artifacts remained in the underflight data after masking. This cloud contamination problem was amplified when comparing two images because missed clouds or cloud shadows in one image were unlikely to be masked in the other due to the shifts in the cloud and cloud shadow positions. Buffering clouds and cloud shadows in each individual Fmask image by 50 pixels cleaned up most of the noise present in both images and ensured that the remaining area contained only clear observations in both satellite acquisitions. The choice of 50 pixels was a relatively arbitrary decision, but it was the smallest buffer size tested that removed the majority of obvious data contamination.

The cloud screened reflectance observations were used to generate several vegetation indices for analysis, including the Normalized Difference Vegetation Index (NDVI Tucker, 1979), Enhanced Vegetation Index (EVI Huete et al. 2002), Normalized Burn Ratio (NBR Key and Benson, 2005), and Normalized Difference Moisture Index (NDMI) indices. The Greenness and Wetness components of the Tasseled Cap transforms (Kauth and Thomas, 1976) were also calculated using Landsat TM surface reflectance transform coefficients from

Crist (1985). We tested using the tasseled cap coefficients for ETM+ at-satellite reflectance from (Huang et al., 2002), but the outcomes were not meaningfully 
different. Linear regressions were constructed to estimate the relationship between Landsat 7 and Landsat 8 reflectance values as a gain and bias. We were concerned with what a corrective equation might look like, so we did not restrict the functional form of the regression to only a gain or a bias. Regression 95\% confidence intervals for the slope and intercept estimates were generated using 1,000 bootstrap samples of each dataset. The lower and upper confidence bounds were taken as the $2.5 \%$ and $97.5 \%$ percentiles of the sorted bootstrap parameter estimates.

\subsubsection{Cirrus cloud characterization}

We also used the underflight data to observe the spectral characteristics of cirrus cloud observations in Landsat data that would not be picked up without the new cirrus band on Landsat 8. We extracted pixels classified as clear land in Landsat 7 and Landsat 8 CFmask results as reference examples for clean observations. Pixels classified as clear land or clear water within the Landsat 7 CFmask image that were classified as cirrus clouds within the Landsat 8 CFmask image were also extracted. To account for errors in the CFmask images and movement of the clouds and cloud shadows between image acquisitions, we eroded the boundaries of CFmask labels by 20 pixels. This erosion helped ensure that the disagreement between the two CFmask images was the result of detection capacity and not random error or spatial mismatches. Not all scenes acquired during the underflight period contained cirrus clouds or contained enough disagreement about cirrus cloud coverage to perform our analysis, so we were limited to two scenes in Mendoza Province, Argentina (P230R084) and Santa Cruz Province, Argentina (P230R094). Visual inspection of these images showed that cloud masks in both scenes shared similar patterns. Areas of dense cirrus cloud cover were identified as cloud cover in Landsat 7 masks and cirrus cloud cover in Landsat 8, but areas of thin cloud cover were misidentified as clear land in Landsat 7 and correctly classified as cirrus cloud in Landsat 8. While the cirrus cloud classification may suffer from false positives over bright targets in dry environments or over high elevation targets (Zhu et al., 2015b), 
the mean elevation of the two scenes was relatively low $(440 \mathrm{~m}$ and $675 \mathrm{~m}$ for P230R084 and P230R094, respectively) and we are confident from visual inspection that the vast majority of pixels identified as clear land and cirrus cloud in Landsat 7 and Landsat 8 masks were omitted in the Landsat 7 cloud masks.

Observations labeled clear in one CFmask image but cirrus cloud in another represent difficult to detect noise within historical Landsat data that may now be routinely filtered using OLI's cirrus band. These data were analyzed using bivariate plots comparing the spectral reflectance and brightness temperature from Landsat 8 in combinations of spectral bands. Plotted points were colorized according to the classification in Landsat 8's CFmask image. We added contour lines to describe the overlap of the clear land and cirrus cloud observations by delineating the two dimensional space occupied by $95 \%$ of the observations in each population. We used a Gaussian kernel density estimate to approximate the distribution of each population in bivariate space (Silverman, 1986). The 95\% percent contour lines were estimated as the 95th percentile of the estimated distribution from the two dimensional kernel density estimate.

\subsection{Landsat time series}

Landsat time series were analyzed using a Python implementation of the Continuous Change Detection and Classification (CCDC) algorithm (Zhu and Woodcock, 2014, Zhu et al., 2015c). The CCDC algorithm attempts to detect abrupt changes in a time series using an "online" monitoring approach by sequentially comparing reflectance observations against a prediction. Reflectances are predicted using a simple Fourier style model with independent variables representing the overall reflectance (intercept), the change in reflectance over time (slope), and the intra-annual variation in reflectance due to phenology or sunsensor geometry (harmonics):

$$
\hat{\rho}_{i}=\beta_{0}+\beta_{1} x_{t}+\sum_{j \in N}\left[\beta_{2 j} \cos \left(\frac{2 \pi j}{T} x_{t}\right)+\beta_{2 j+1} \sin \left(\frac{2 \pi j}{T} x_{t}\right)\right]+\varepsilon_{t}
$$

where $\hat{\rho}_{i}$ is the predicted reflectance or temperature in each spectral band $i$, 
$x_{t}$ is the ordinal date of each observation, $N$ is a set of integers specifying the frequency, $j$, of the Fourier series harmonics, $T$ is the number of days in a year (365.25), and $\varepsilon_{t}$ is the residual error term for each observation.

This study used a pair of year and half year $(N=\{1,2\})$ harmonics to be able to capture most seasonal vegetation patterns while remaining simpler than the full 8 coefficient model used in Zhu et al. (2015c). The CCDC algorithm employs the Least Absolute Shrinkage and Selection Operator (LASSO) regularization method to reduce overfitting by estimating coefficients that minimize the residual sum of squares while also penalizing the absolute magnitude of the coefficients (Tibshirani, 1996). LASSO can provide coefficient estimates of exactly zero, and this type of model selection helps allow CCDC to use a possibly overly specified but generic model for all time series.

To help provide a stable and robust initial estimate of land surface reflectance, the CCDC algorithm screens the training period using a multitemporal filtering algorithm designed to remove any cloud and cloud shadows that might have been missed by Fmask (Zhu and Woodcock, 2014). After the initial time series model has been fit during this training period, successive observations are compared against the forecast prediction. A difference between the observation and prediction is significant if the $l^{2}$-norm, or Euclidean norm, of forecasted residuals scaled by model RMSE across the set of tested bands is above a specified threshold:

$$
T_{\text {crit }}>\sqrt{\sum_{i \in B}\left(\frac{\hat{\rho}_{i}-\rho_{i}}{R M S E_{i}}\right)^{2}}
$$

where $T_{\text {crit }}$ is the significance critical threshold, $B$ is a set of spectral bands used in the change detection, $\hat{\rho}_{i}$ and $\rho_{i}$ are the predicted and observed reflectances or values in band $i$, and $R M S E_{i}$ is the time series model RMSE for band $i$.

If observed reflectances significantly differ from the forecasted reflectances for some number of consecutive observations, CCDC places a break in the time series and begins trying to fit another time series model after the disturbance. 
The breaks or disturbances in the time series create distinct segments through time that should correspond to a period of stable land cover or land surface condition. These segments in the time series can then be classified into land cover categories using attributes derived from the time series models, including the coefficients and Root Mean Squared Error (RMSE) of the time series models estimated for each Landsat band. The estimated time series model coefficients and RMSE estimates, and not the change detection, are the focus of this study. For further information and detail about the Continuous Change and Classification Detection algorithm, including how it detects change, the reader is referred to Zhu and Woodcock (2014) and to Zhu et al. (2015c) for algorithm changes and improvements.

To address the questions of the effect of spectral differences between Landsat 7 and Landsat 8 in time series, we fit time series using CCDC to five different post-launch scenarios. All five time series were initialized between 2008 and 2013 using only Landsat 7 data, but were continued after the launch of Landsat 8 with different sets of Landsat observations:

1. Only Landsat 7 data post-launch

2. Only Landsat 8 data post-launch

3. Combined Landsat 7 and Landsat 8 data post-launch

4. Only Landsat 8 data post-launch, excluding information from the cirrus band in the Fmask images for Landsat 8 data

5. Combined Landsat 7 and Landsat 8 data post-launch, excluding information from the cirrus band in the Fmask images for Landsat 8 data

The first scenario containing only Landsat 7 data was used as a normalizing factor to isolate the influence of including Landsat 8 data within the time series of scenarios two and three. Intercept and RMSE values for scenarios two and three were normalized by dividing these estimates by the corresponding intercepts and RMSE values from the Landsat 7 models (scenario one). A value of one for the normalized intercept and RMSE indicate that the inclusion of 
Landsat 8 data (scenario two and three) did not change the quantity of interest. Values above one indicate the quantity was increased relative to just using Landsat 7 and values below one signify a decrease in the quantity. The slope estimates in the CCDC models are usually either zero or very close to zero. To avoid computational issues of dividing by zero, we normalized the slope values by subtracting the slopes estimated using Landsat 8 data (scenarios two and three) by the slope estimated only using Landsat 7 (scenario one). Similarly, scenarios four and five were compared after being normalized by scenarios two and three to understand the effect of improved cloud detection possible with the cirrus band on Landsat 8.

We masked and ignored from the analysis any pixels that changed between 2010 and 2015 as found by the CCDC algorithm because time series following a disturbance can be erratic or noisy. Large variability in the observed target might have created false differences among the continuation scenarios simply due to random chance rather than due to a systematic difference. We took a large random sample of all remaining, stable pixels, and extracted the intercept and slope coefficients and the Root Mean Squared Error (RMSE) of each time series model for comparison.

\section{Results and Discussion}

\subsection{Landsat 8 Underflight}

\subsubsection{Spectral Comparison}

Spectral comparison results for scenes over Nebraska, United States (WRS2 path and row P029R031) and Mendoza Province, Argentina (P230R084) are shown in Figure 1 and 2, respectively. While only the results for these two Landsat scenes are shown in the main text of this article, the patterns observed in these scenes are characteristic of the responses seen in other scenes containing sufficient clear observations of land. Figures and tables showing the spectral responses for all other Landsat scenes acquired are available in the supplementary material (Supplementary Figures 2 - 8). 
The reflectances in the visible wavelengths (blue, green, and red) of the Landsat 8 atmospherically corrected product are consistently darker than reflectances observed in the Landsat 7 data. The largest bias occurs in the blue band and decreases with increasing wavelength from green to red. While the wavelengths measured by the visible bands only changed slightly from Landsat 7 to Landsat 8 (Table .1), atmospheric interference is greatest in the blue band and decreases as wavelength increases. If differences in atmospheric correction are responsible for some of the difference between sensor measurements, it makes sense that the greatest difference is visible in the band that requires the greatest adjustment for scattering and absorption and the LEDAPS and L8SR algorithms use different inputs to parametrize atmospheric constituents. Some proportion of this bias is also likely caused by differences calibration or target specific spectral responses, but estimating the relative contribution of these three causes is outside the scope of this analysis.

The near infrared band, with the largest physical difference in measured wavelengths, did not show considerable bias in Nebraska, United States (P029R031) (Figure 1). However, there was a large and consistent positive bias in the near infrared reflectance in Medoza, Argentina (P230R084) (Figure 2). Summer in Argentina during the month of March most likely has much higher atmospheric water vapor content than the United States during winter. The narrower wavelengths measured by Landsat 8 avoided an atmospheric water absorption feature, so it is understandable that the bias in near infrared reflectance is higher in an environment with more water vapor. The shortwave IR bands may be slightly brighter in Landsat 8 than in Landsat 7 due to the smaller spectral band widths, but the measurements have not changed as significantly as the other bands. The difference in bias across scenes observed in this study is similar to the findings of Flood (2014) that there are regional differences in the sensor bias.

Differences in individual bands between Landsat 7 and Landsat 8 are especially important when considering spectral or vegetation indices because these indices often rely on the contrast between two or more bands. The Normalized 

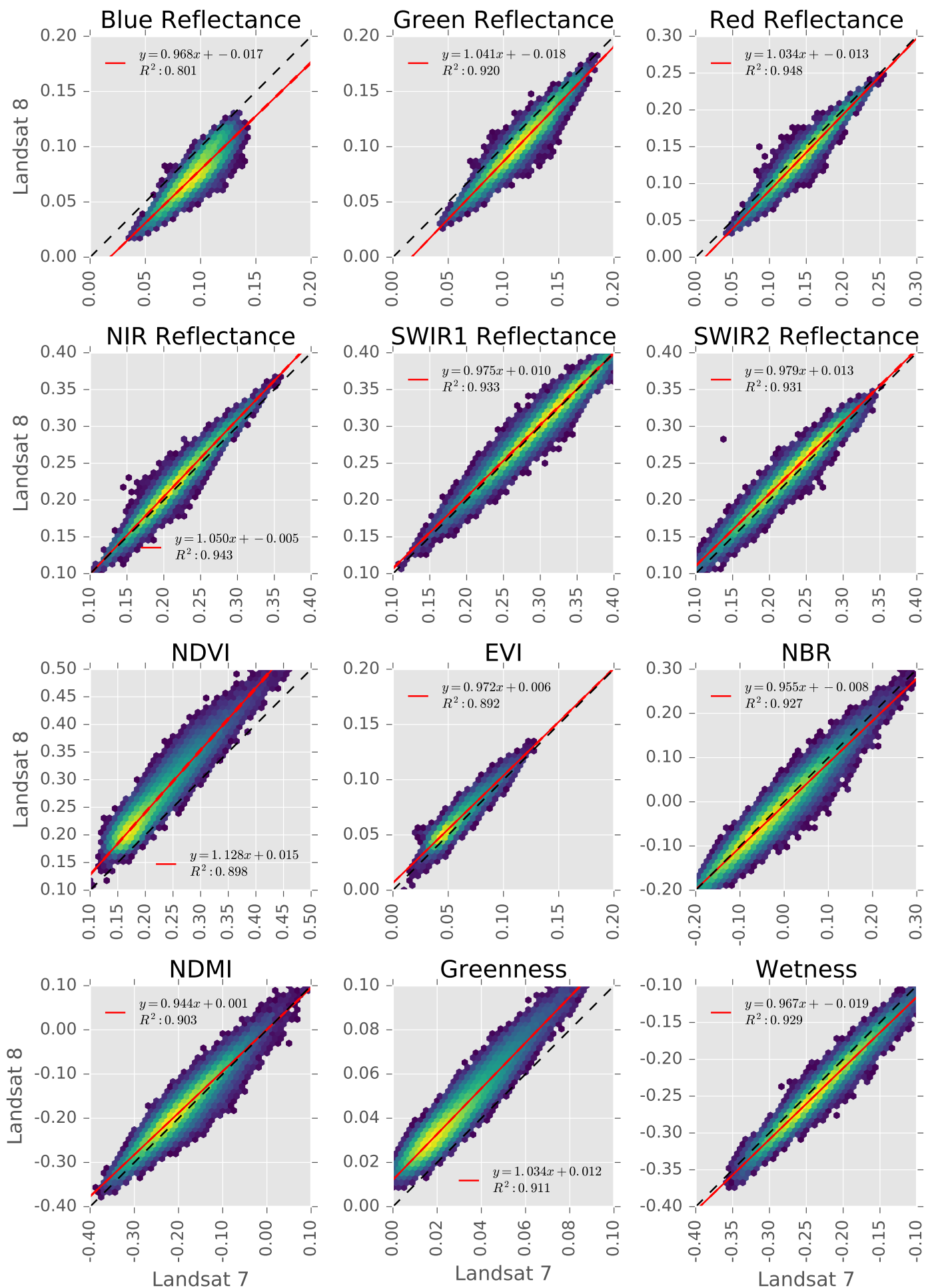

Figure 1: Landsat 7 and Landsat 8 underflight data comparison for Nebraska, United States (P029R031). Regression parameters and $R^{2}$ estimates describing the fitted line are provided in the top left of each plot. The $95 \%$ confidence interval range around the regression estimate is displayed as a dashed line around the regression line, but it may not be visible for small confidence intervals. 

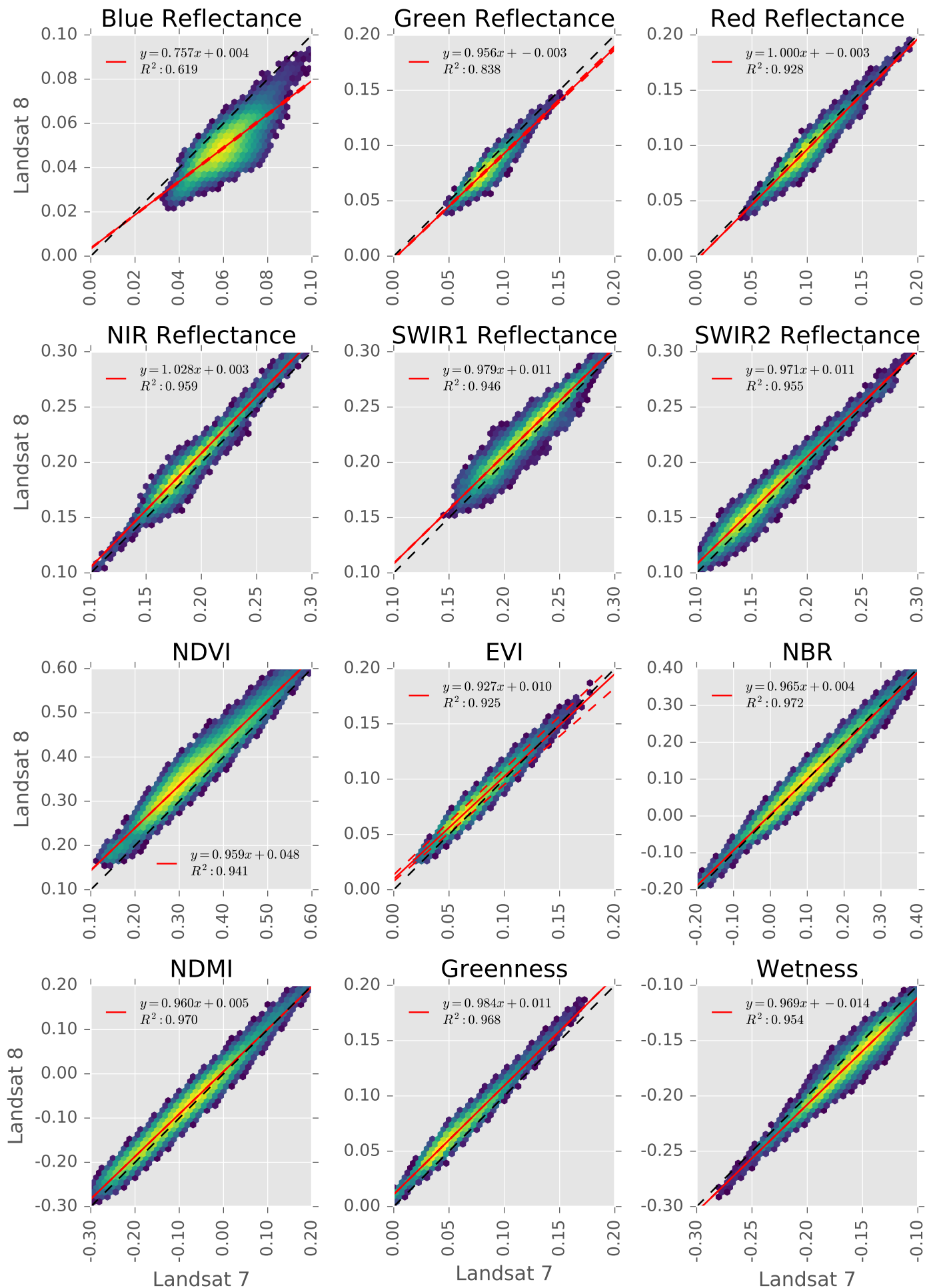

Figure 2: Landsat 7 and Landsat 8 underflight spectral comparison for Mendoza Province, Argentina (P230R084). 
Differenced Vegetation Index (NDVI) relies on the contrasting relationship between the near infrared band and the red band. It appears that the near infrared band and red bands in Landsat 8 are brighter and darker than in Landsat 7, respectively, which enhances the contrast highlighted in NDVI. As such, we see a strong and consistent positive bias in NDVI with Landsat 8 having much higher NDVI. The Enhanced Vegetation Index (EVI) differs from NDVI by utilizing the blue band as an additional normalizing factor that corrects the red band for atmospheric influences. Either by coincidence or as the intention of Huete et al. (2002), it appears that the bias in the blue band between Landsat 8 and Landsat 7 nullifies the bias in the red and near infrared band, resulting in a surprisingly similar EVI across sensors. The Normalized Difference Moisture Index (NDMI) and the Normalized Burn Ratio (NBR) both compare the shortwave infrared with the near infrared using either the first or second SWIR bands, respectively. These vegetation indices show little difference between Landsat 7 and Landsat 8. If there is a difference in the shortwave infrared bands between sensors, it appears to be in the same positive direction as the bias in the near infrared, resulting in a cancellation effect. The Tasseled Cap Greenness transform displays the same strong positive bias as the NDVI while the Wetness Tasseled Cap transform is darker in Landsat 8 than in Landsat 7. The Wetness transform for Landsat 7 places little weight on the red and near infrared bands in favor of contrasting the blue and green with the two shortwave infrared bands. Because the blue and green bands are darker in Landsat 8 than in Landsat 7 and the shortwave infrared bands might be brighter in Landsat 8, this contrast is enhanced and creates a small bias in the Wetness transform.

The effect of increased radiometric resolution is readily apparent when comparing reflectance estimates or spectral indices between sensors. Scatter plots of the data shown using hexbin plots in 1 and 2 both displayed a visual striping pattern distributed across the $\mathrm{X}$ axis that was not simply a visual artifact in the plot, but a result of the increased quantization possible with Landsat 8's 12-bit radiometric resolution. When the OLI instrument converts the continuous measurement of radiance by its detectors into digital numbers, the 12-bit 
radiometric resolution offers sixteen times the digitization detail compared to Landsat 7. The increased detail is carried through when converting from digital numbers back into radiance and the precision remains when converting to surface reflectance. The underflight spectral comparison figures for a Landsat scene over the coast of Greenland (P013R031), included in the supplementary material (Supplementary Figure 3), contains the best example of the effects of increased radiometric resolution as this striping is shown even when using a hexbin plot. Reflectance estimates from Landsat 8 do not display any striping throughout the very low range of reflectance measured $(2-8 \%)$ in the shortwave infrared while Landsat 7's measurements contain distinct discrete gaps representative of the lower quantization. Improvements to the radiometric resolution on OLI thus enhance detection capabilities by allowing the delineation of very similar, previously indistinguishable, targets.

\subsubsection{Cirrus cloud characterization}

We explored the spectral properties of clear land observations and those affected by cirrus clouds by plotting observations of both targets in bivariate combinations of spectral bands available in the Landsat 8 underflight data (Figure 3). Observations affected by cirrus clouds differ most from clear land observations in the visible wavelengths as seen in the high degree of separation within bivariate plots containing only the visible bands. The blue band, specifically, shows the largest difference between the two populations (subfigures A through E). Cirrus clouds, as expected (Gao et al. 1993, 1998; Gao and Li, 2000 ), increase the reflectance in visible wavelengths, but this increase is not very substantial. The centers of the cirrus cloud and clear land populations differ by approximately $4 \%$ reflectance in the blue band, about $3 \%$ in the green band, and by even less in the red band. It is interesting to note that even in the visible bands the values of observations affected by cirrus clouds are still within the range of unaffected observations, which helps explain why it is so hard to detect cirrus clouds in any automated fashion in the absence of a cirrus band like the one on Landsat 8 . The distinction between clear land and 
cirrus clouds omitted by Landsat 7 in P230R094 is even smaller, but there is still a difference in the means of the two populations (Supplementary Figure 9). The near infrared and shortwave infrared bands provide no separation alone as the populations completely overlap when only using the infrared bands. The thermal band shows the largest separation between the two populations of approximately half a degree Celsius (subfigures F, K, and O). If our objective were to find cirrus clouds in our dataset without the use of the cirrus band on Landsat 8 , the shorter and thermal wavelength bands would be most valuable. The opposite perspective to this conclusion is that if we wish to avoid cirrus cloud contamination influencing our datasets from all Landsats prior to Landsat 8 we would exclude the visible bands and thermal bands from our analysis whenever possible and rely heavily on the NIR and SWIR bands as these appear to be least affected by cirrus clouds missed without the use of a cirrus band.

\subsection{Landsat time series}

\subsubsection{Impact of Landsat 8 on time series of Landsat observations}

Figure 4 shows an example time series for one pixel in an undisturbed evergreen forest stand in Colorado (P034R032) in red reflectance and NDVI. The regression models used are described by equation 1, but some model coefficients, such as the sinusoidal terms used to model seasonality, may be estimated as 0 due to the regularization performed by the LASSO method. As seen in the underflight data, the observations from Landsat 8 are darker in the red band, creating higher NDVI values. The time series models show a small difference in the intercept estimates and a much larger difference in the slope estimate that adjusts for the differences between sensors. The unexplained variation due simply to the sensor differences increases the Root Mean Squared Error (RMSE) in the models. Only observations in the visible bands and the NDVI were affected by sensor differences for this specific target. Time series models for the NIR, SWIR1, SWIR2, and thermal bands and for the EVI, NBR, and NDMI indices were not different between the Landsat 7 only (scenario one) and combined sensor (scenario two) datasets. This example is included to demonstrate the 

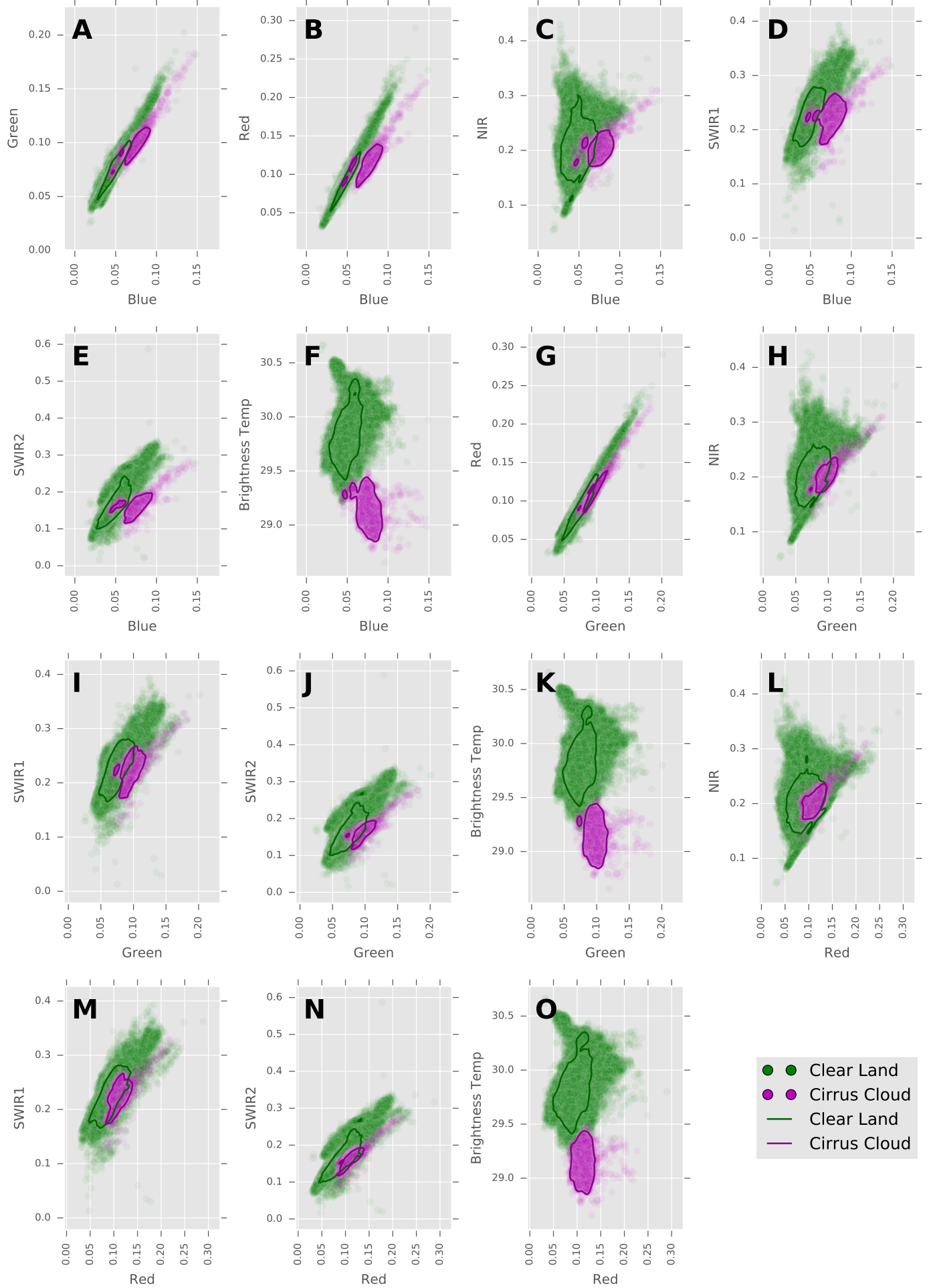

Figure 3: Clear land and cloud cirrus spectral properties for Mendoza Province, Argentina (P230R084). Contour lines contain 95\% of the data in the bivariate distribution space for data labeled as clear land (green) and cirrus cloud (magenta) in Landsat 8 CFmask images. 
influence of observation differences on time series model parameter estimates. Results for millions of pixels across more study sites in all spectral bands and vegetation indices are given in this section.

Three time series datasets covering four WRS-2 scenes initialized using Landsat 7 data and continued after the launch of Landsat 8 with either Landsat 7 (scenario one), Landsat 8 (scenario two), or both Landsat 7 and Landsat 8 data (scenario three) were analyzed with the Continuous Change Detection and Classification (CCDC) algorithm. Intercept, slope, and RMSE estimates for scenarios two and three containing data from Landsat 8 were normalized relative to Landsat 7 results as described in section 3.2 In essence, we are treating the use of only Landsat 7 as the baseline for comparisons with Landsat 8 or the combination of Landsats 7 and 8. A value of one for the normalized intercepts and RMSE values indicates no difference between scenarios, while values above or below one values indicate the attribute is brighter or darker when including Landsat 8 data. A value of zero in normalized slope estimates indicates no change between scenarios while positive or negative values indicate an increase or decrease in the time series slope relative to only using Landsat 7 data. If the introduction of Landsat 8 data into time series of Landsat 7 data caused no difference, histograms of these normalized parameter estimates from pixels within each scene should approximate a normal distribution centered on one for intercepts and RMSE or zero for slopes. Model parameters greatly affected by the inclusion of Landsat 8 observations should produce histograms that are offset from the "no change" normalized values of one or zero.

Time series model intercept, slope, and RMSE attributes for a scene in Colorado, United States (P034R032) are shown in Figures 5, 6, and 7, respectively and confirm the results previously found in the underflight data comparison. The blue, green, and red bands on Landsat 8 were consistently darker than the same measurements in Landsat 7 data in the underflight data, and this consistent offset impacts the modeling results in time series scenarios. Time series model intercepts for the blue, green, and red bands shown in figure 5 are unusually much darker due to the inclusion of Landsat 8 data as shown by the 

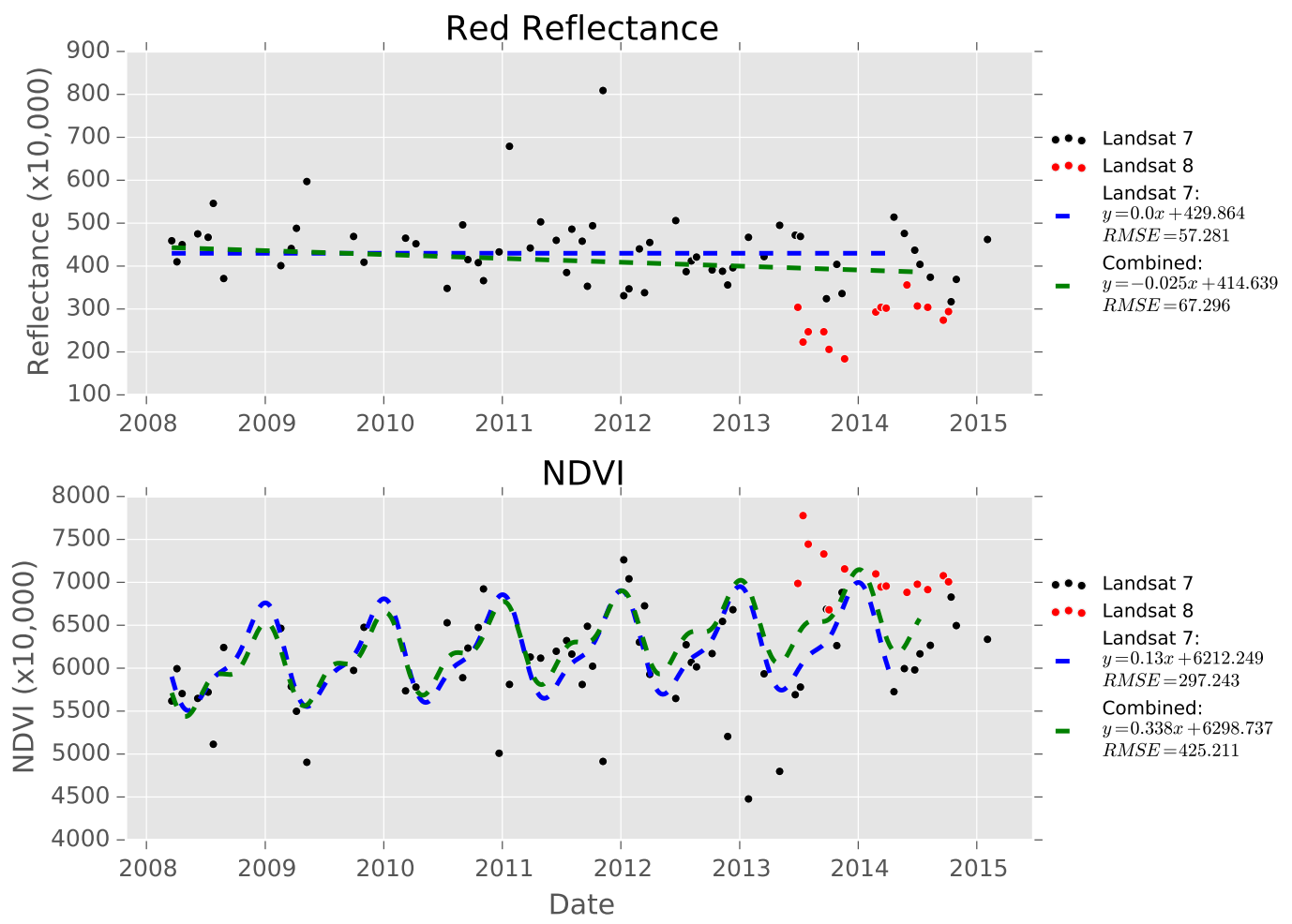

Figure 4: Example time series of an evergreen forest stand in Colorado, United States (P034R032). Observations from Landsat 7 and Landsat 8 are shown in black and red, respectively. CCDC model regressions for time series including only Landsat 7 data (scenario 1) and both sensors (scenario 2) are plotted in blue and green. Model slope, intercept, and RMSE estimates are included in the figure legend. 
shift in the median of the histograms from 1.0 to values between approximately 0.90 and 0.96 . The median normalized intercept estimated for the blue band when continuing Landsat 7 time series with only Landsat 8 data (scenario two), for example, is $10 \%$ darker than the intercept that would have been estimated when using exclusively Landsat 7 data. Time series continued after the launch of Landsat 8 with both Landsat 7 and Landsat 8 (scenario 3) are less affected than with Landsat 8 data alone as seen in the reduction in the shift of the blue colored histogram (scenario three) relative to the red colored histogram (scenario two). However, the combined scenario still contains a bias in the visible band intercepts. The histograms of the normalized intercepts in the near infrared and shortwave infrared bands are centered approximately at one and are approximately normally distributed. Thus, the NIR and SWIR bands show little signs of bias relative to Landsat 7 and do not behave difference under the Landsat 8 or combined sensor scenarios. Among the vegetation indices, only NDVI is substantially affected and is characteristically brighter in Landsat 8 than in Landsat 7 as the histogram of normalized NDVI values is centered at approximately 1.03 to 1.04 . While the thermal band is slightly darker for the time series in Colorado, United States, the pattern was not consistent in other Landsat scenes (Supplementary Figures 10, 13, and 16).

While the use of Landsat 8 in regressions might affect the overall mean reflectance, measured as the intercept of the regression, any differences between Landsat 7 and Landsat 8 are best explained using a slope estimate because the Landsat 8 data are placed at the end of the time series. Figure 6 shows that the Landsat 8 observations placed at the end of the Landsat 7 time series create a spurious time trends for many of the bands and indices analyzed. The darker observations in the visible bands in Landsat 8 create false positive decreasing time trends in both continuation scenarios, although the influence in the combined scenario is less pronounced. The median slope response for the near infrared band is approximately zero indicating no bias in the slope coefficient. While the shortwave infrared bands appear to have a negative bias in the results for Colorado, United States (P034R032), this pattern was not 

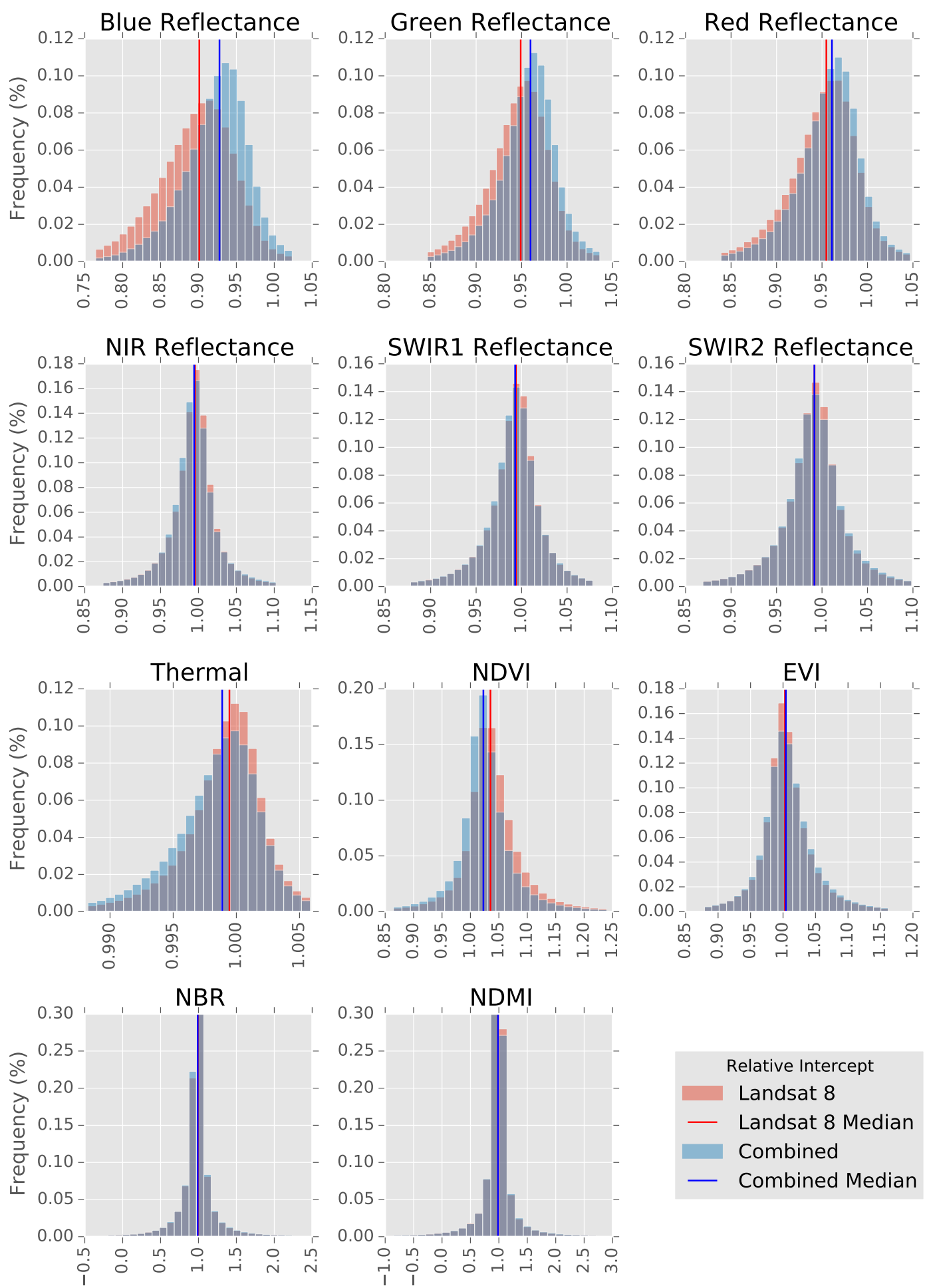

Figure 5: Normalized intercept estimates for time series models in Colorado, United States (P034R032) used to assess spectral differences caused by including Landsat 8 data. The Landsat 8 only and combined Landsat 8 and Landsat 7 intercept estimates were normalized by dividing by the intercepts of time series models using only Landsat 7 data. The Y-axis was truncated at $30 \%$ to give better resolution to smaller frequency bins. 
present in the three other scenes analyzed (Supplementary Figures 11, 14, and 17). Repeating the patterns previously observed, NDVI is highly affected by differences in Landsat 8's reflectance in the visible bands but the effect does not carry over to EVI. The NBR and NDMI indices, despite not showing an effect in the time series intercept coefficient, show a slight positive time trend when using Landsat 8 data. The positive time trend in NBR and NDMI was also observed for two scenes over Florida (P016R041) and Mississippi (P023R037), but not in California (P043R034) (Supplementary Figures 11, 14, and 17). The distribution of thermal band slope coefficients for Colorado has a long negative tail, but this phenomenon is not observed in Florida or Mississippi and the slope distribution for California shows an opposite long positive tail. These results that show spurious time trends, especially in vegetation indices, can be caused by differences in reflectance across Landsat 7 and Landsat 8 reinforce the false positive slopes found in time series analysis over Canadian boreal forest using Landsat 5 and Landsat 7 (Sulla-Menashe et al. 2015).

The change in RMSE of time series models using Landsat 8 (scenarios two and three) relative to pure Landsat 7 time series models (scenario one) varies depending on how different a particular band or vegetation index looks in Landsat 8 and Landsat 7. For Colorado (P034R032), just as we see the largest difference in time series model intercepts and slopes in the visible bands and NDVI, we also see increases in the RMSE of time series models using these data (Figure 7). The other scenes in Florida (P016R041) and Mississippi (P023R037) share this pattern of increase in the unexplained variance in the visible and NDVI data (Supplementary Figures 12 and 15). The scene in California (P043R034) shows weaker evidence for increased noise when using the combined data scenario (scenario three) and no sign of increasing noise when just using Landsat 8 data post-launch (scenario two) (Supplementary Figure 18). The estimated intercept and slopes for the near infrared and shortwave infrared bands did not differ among scenarios so we would expect little change in the RMSE of these models. The EVI, which has consistently shown the smallest smallest differences between Landsat 7 and Landsat 8, does not show increases in model 

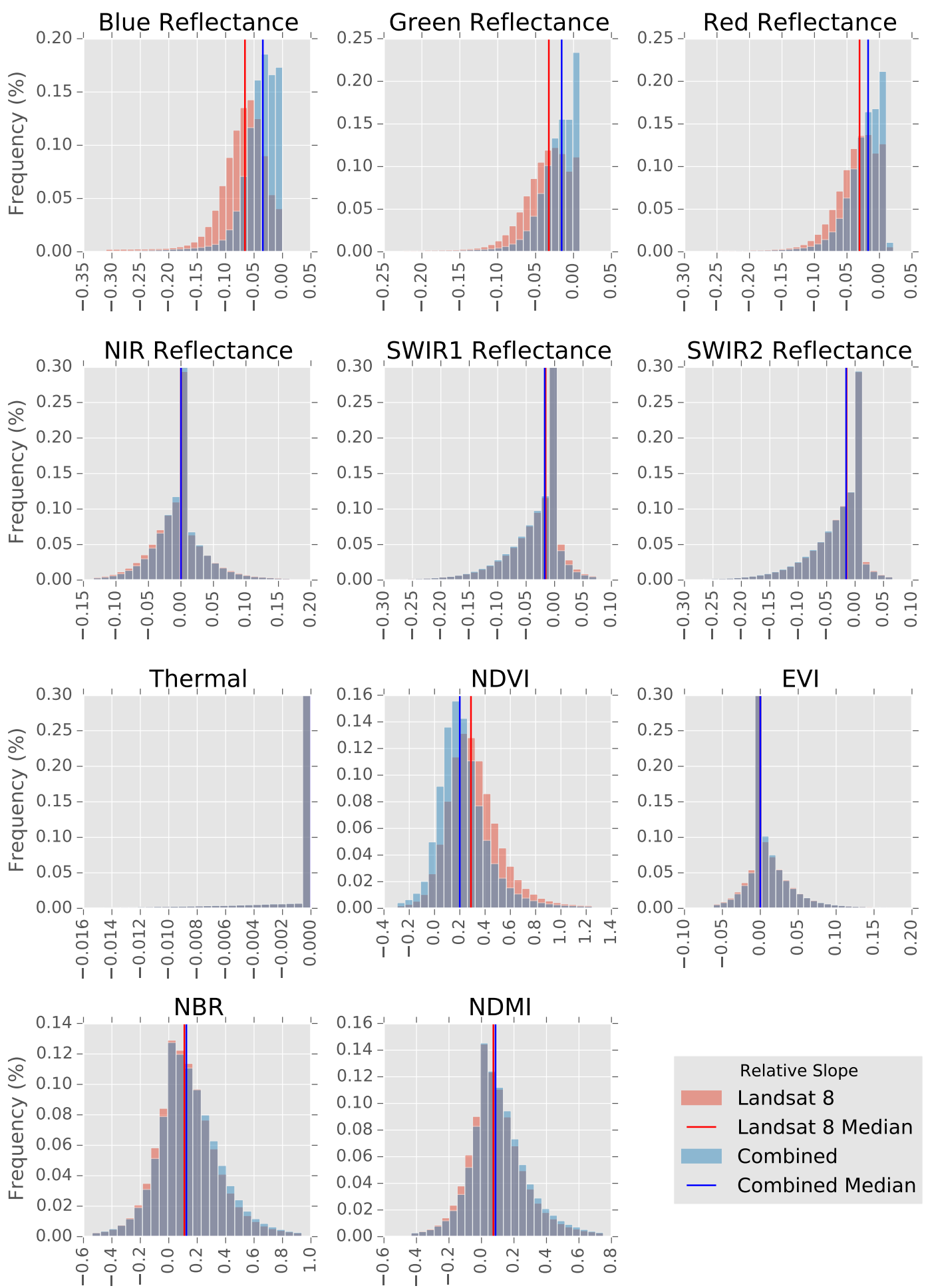

Figure 6: Normalized slope estimates for time series models in Colorado, United States (P034R032) used to assess spectral differences caused by including Landsat 8 data. The Landsat 8 only and combined Landsat 8 and Landsat 7 slope estimates were normalized by subtracting the slopes from time series models using only Landsat 7 data. The Y-axis was truncated at $30 \%$ to give better resolution to smaller frequency bins. 
RMSE relative to Landsat 7. While NBR and NDMI showed a positive time trend in Colorado, Florida, and Mississippi, this bias relative to Landsat 7 has only increased the RMSE of models in Mississippi. The influence of changes in the thermal band may affect the RMSE of models, but the magnitude and direction of this effect is not consistent among scenes analyzed.

A systematic difference between Landsat 8 and Landsat 7 observations affects time series analysis in three ways. First, a consistently darker or brighter sequence of Landsat 8 observations will eventually affect the mean reflectance of a time series. Variation in reflectance due to the dataset of origin rather than variation in physical attributes hampers inference. For example, if a forest were slightly degraded in 2013, the mean NDVI of a time series after the disturbance might be the same as the time series before the disturbance because the NDVI in Landsat 8 is brighter than the NDVI in Landsat 7. The effect of biases in Landsat 8 relative to Landsat 7 is especially concerning with regard to the time trend or slopes of time series models. Second, consistently darker or brighter observations from Landsat 8 placed at the end of an existing, stable time series of Landsat 7 data are shown to induce a false positive trend in reflectance through time. Time trends in reflectance or vegetation indices have been used as a proxy or indicators of changes in ecosystem function and structure, including vegetation greening, browning, recovery, or degradation. Inference of temporal trends will require relative calibration to ensure trends are not simply due to sensor differences. Lastly, bias in observed reflectance between the two sensors also hinders detection of land cover change in time series analysis. Change detection methods that use a regression framework to predict reflectance based on time series models (as in Verbesselt et al. (2012); Zhu and Woodcock (2014)) identify a time series break occurs if predictions differ significantly from observations. Bias in reflectance values between sensors adds an unexplained source of variability to the time series that broadens the range of nonsignificant differences between observed and predicted values. A more familiar comparison is the decreased ability to infer separation between reflectances before and after a land cover change in a paired t-test if each population has larger within-group 

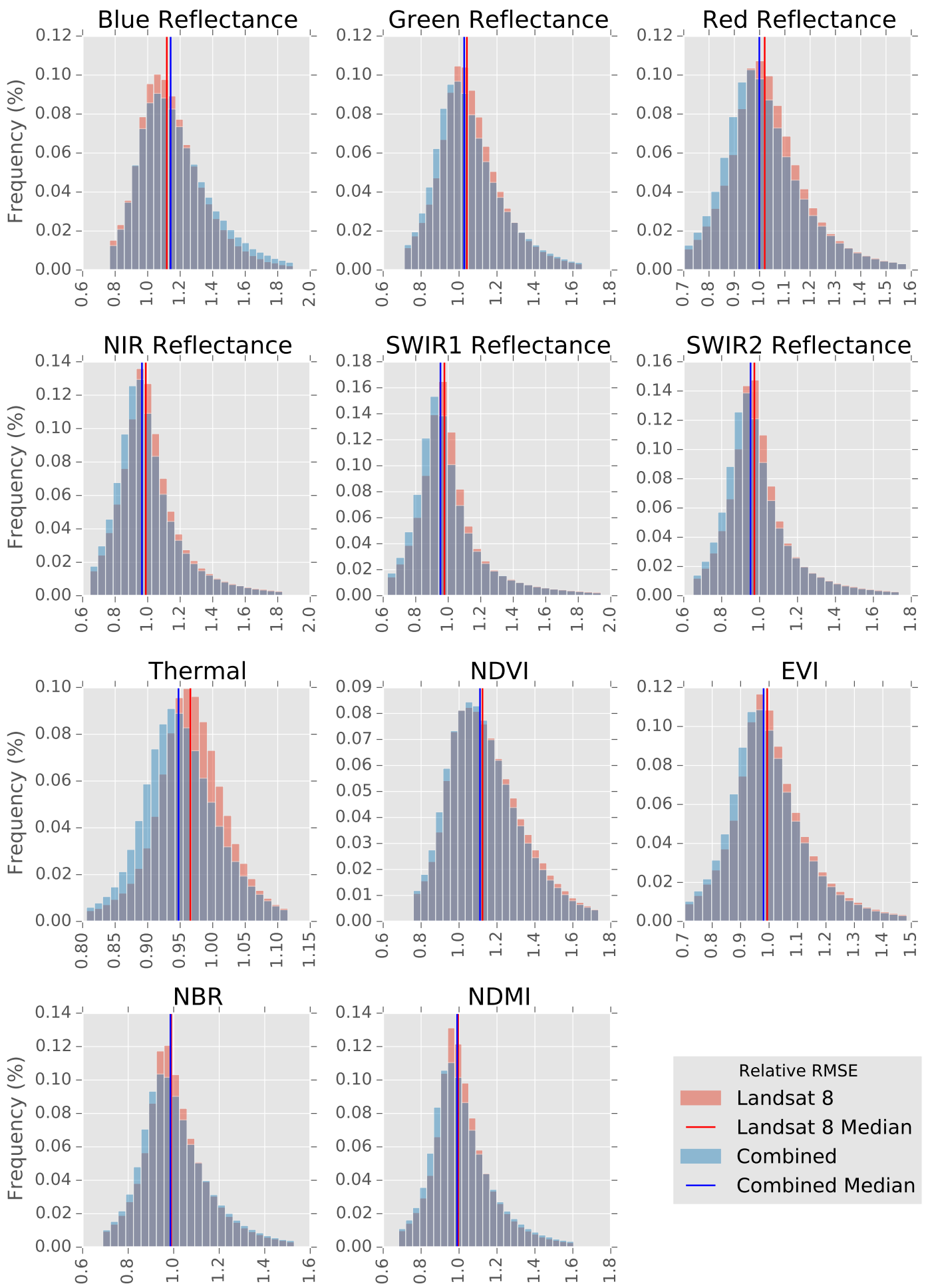

Figure 7: Normalized RMSE estimates for time series models in Colorado, United States (P034R032) used to assess spectral differences caused by including Landsat 8 data. The Landsat 8 only and combined Landsat 8 and Landsat 7 RMSE estimates were normalized by dividing by the RMSE from time series models using only Landsat 7 data. The Y-axis was truncated at $30 \%$ to give better resolution to smaller frequency bins. 
$\hat{\rho}_{i}=\beta_{0}+\beta_{1} x_{t}+\sum_{j \in N}\left[\beta_{2 j} \cos \left(\frac{2 \pi j}{T} x_{t}\right)+\beta_{2 j+1} \sin \left(\frac{2 \pi j}{T} x_{t}\right)\right]+\beta_{\text {dummy }} D_{\text {sensor }, t}+\varepsilon_{t}$

variance.

Time series algorithms that do not rely on surface reflectance observations or perform image normalization prior to analysis may not be as significantly affected by cross-sensor differences. For example, while the Vegetation Change Tracker (VCT) (Huang et al., 2010) uses surface reflectance, imagery also undergoes a normalization using examples of dense and dark forests prior to analysis. The LandTrendr algorithm (Kennedy et al. 2010 ) normalized all Landsat imagery to a reference image using the Multivariate Alteration Detection and Calibration (MADCAL) algorithm (Canty et al., 2004). Techniques which rely on modeled attributes, such as forest cover fraction, derived from Landsat imagery may also avoid image normalization if separate models are used for each sensor. Normalization might not be required, however, if the bias associated with a particular sensor can be modeled as a time series component. One extremely simple method that could account for the difference in reflectance associated with a categorical variable is the use of a "dummy" variable within each time series model. A "dummy", or treatment, variable acts as an additional intercept estimate specific to one category, or for Landsat 8 in this case. When the "dummy" variable is incorporated into the CCDC regression model, the regression model is modified from equation 1 as:

where:

$$
D_{\text {sensor }, t}= \begin{cases}1, & \text { if Landsat } 8 \\ 0, & \text { otherwise }\end{cases}
$$

This "dummy" variable estimate would compensate for sensor specific differences allowing for a more efficient estimate of the time series model slope and intercept, provided that the difference in sensor behavior can be modeled 

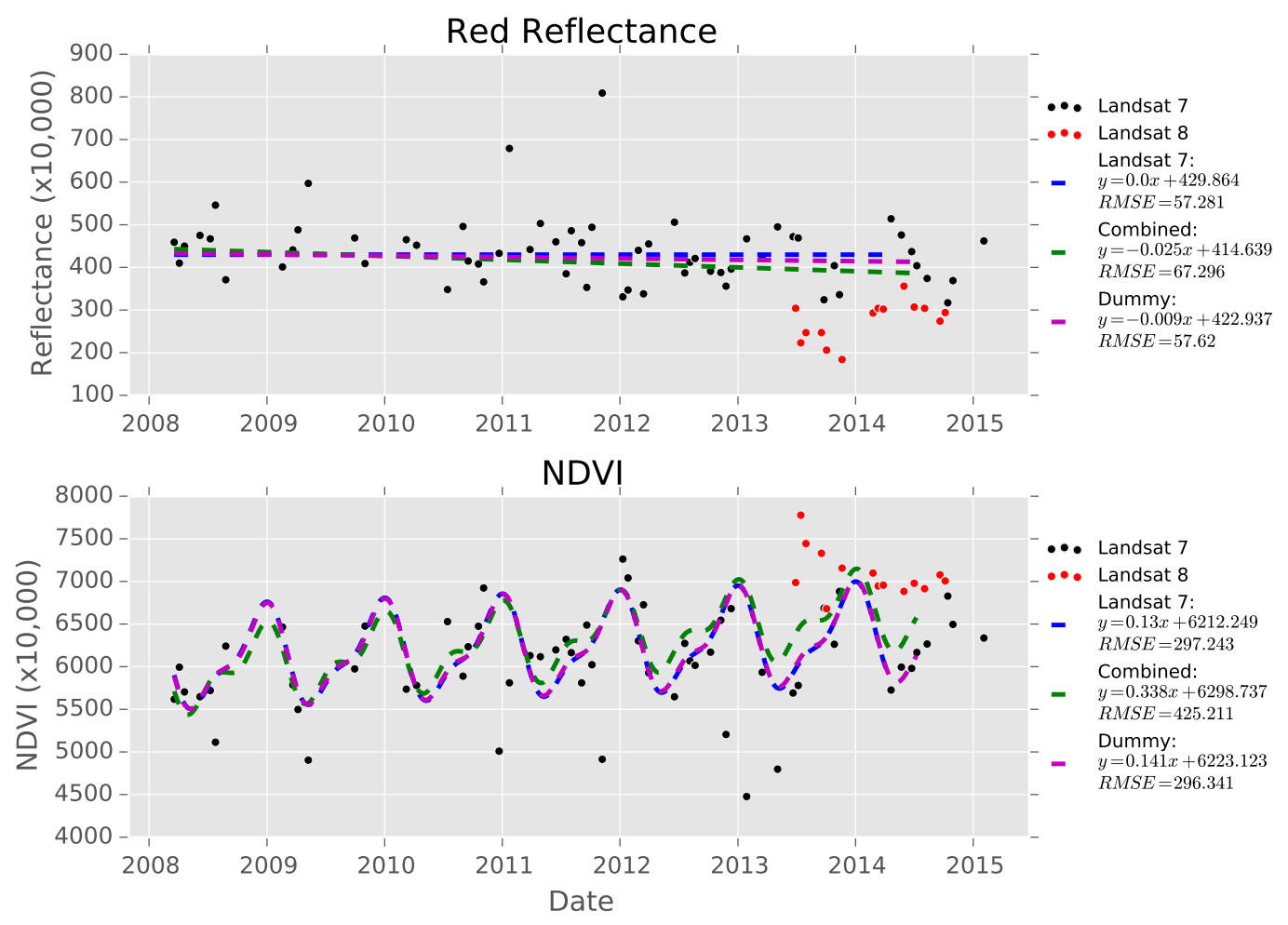

Figure 8: Example time series of an evergreen forest stand in Colorado, United States (P034R032). Observations from Landsat 7 and Landsat 8 are shown in black and red, respectively. CCDC model regressions for time series including only Landsat 7 data (scenario 1) and both sensors (scenario 2) are plotted in blue and green. The magenta regression line includes a dummy variable that captures the reflectance differences between Landsat 7 and Landsat 8 as an additional intercept. The dummy variable estimates were -94.3409 and 1169.12 for red and NDVI, respectively, which offset the bias in Landsat 8 measurements relative to Landsat 7 . 
as a fixed offset. Figure 8 shows the same time series over an undisturbed evergreen needleleaf stand as 4, but with an additional regression line estimated using a Landsat 8 "dummy" variable. "Dummy" variable coefficient estimates for Landsat 8 are negative in the red band to account for a darker measurement and positive for NDVI to account for a brighter measurement. The estimated slope in the red band does not match the slope estimated in the exclusively Landsat 7 data scenario, but the "dummy" variable accounts for the spurious time trend in the NDVI time series while greatly reducing the RMSE of both models. Much more work is required to understand the potential for these sensor specific intercepts to abate problems in time series due to sensor disagreements, but such a solution would be an easy and quick way of synthesizing the datasets without the need for more advanced cross-calibration. This approach also has the advantage of being estimated per pixel within a period of stable land cover condition so that target specific effects due to the shifts in the spectral bandpasses should be accounted for.

\subsubsection{Impact of cirrus cloud detection}

The characterization of cirrus cloud spectral impacts from the Landsat 8 underflight data (section 4.1.2 shows that cirrus clouds increase the reflectance of the visible bands but have negligible effects in the infrared bands. As a result, we expect time series containing cirrus clouds to positively bias the estimates of the intercept and slopes in the visible bands while increasing the RMSE of these models.

Figures 9, 10, and 11, show the time series model intercepts, slopes, and RMSE estimates for scenarios four and five which did not use cirrus band information in the Fmask cloud masks for a Landsat scene in Colorado, United States (P034R032). The intercepts and RMSE estimates were normalized by dividing these estimates by the same estimates from time series models using the cirrus band information (scenarios two and three). The slope coefficients were scaled by taking the difference between scenarios four and five and scenarios two and three, respectively. 
The distribution of the relative intercepts for the visible bands have longer tails above the value of one, especially for the combined Landsat 7 and Landsat 8 data post-launch scenario (scenario 3). The near infrared and shortwave infrared bands appear to have less skew toward either side in the distribution. The intercepts in time series of brightness temperature appear colder without cloud screening using the cirrus band, demonstrated by the skew toward values less than one. Pixels affected by cirrus clouds appear to have reduced the intercept estimate of the NDVI, likely driven by the bias toward brighter values in the red band. The EVI, NDMI, and NBR vegetation indices do not appear to be have biased estimates for the time series model intercepts. The slopes of time series excluding the cirrus band relative to time series including the cirrus band show the same patterns as the intercept estimates (Figure 10) with large differences the visible bands and NDVI slope estimates. Eliminating cirrus clouds from time series images also contributes toward lowering the RMSE of time series models as shown in Figure 11. The skew in the distribution of relative RMSE estimates shows that many of the time series contain more noise without the cirrus band in all bands and indices, but especially in the visible bands and NDVI.

We did not specifically limit our analysis of time series attributes to pixels containing observations identified as cirrus clouds within the time series. Instead, we drew a random sample of pixels within each scene. As such, we do not expect there to be a systematic shift in slopes, intercepts, and RMSE estimates within the time series models not using cirrus information in the Fmask images relative to time series models that did mask cirrus clouds. The shifts in the tails of the relative distributions of these time series variables, positive in the visible bands and the negative in NDVI, are strong evidence to the benefits of the cirrus band. Landsat 8 observations will be much less noisy than observations from previous sensors and this difference might affect future analysis. Measurements in the visible bands from Landsat 8, integrated over enough time, are especially likely to be darker than the response in TM and ETM+, all else equal, simply due to this enhanced screening. The development of methods to 

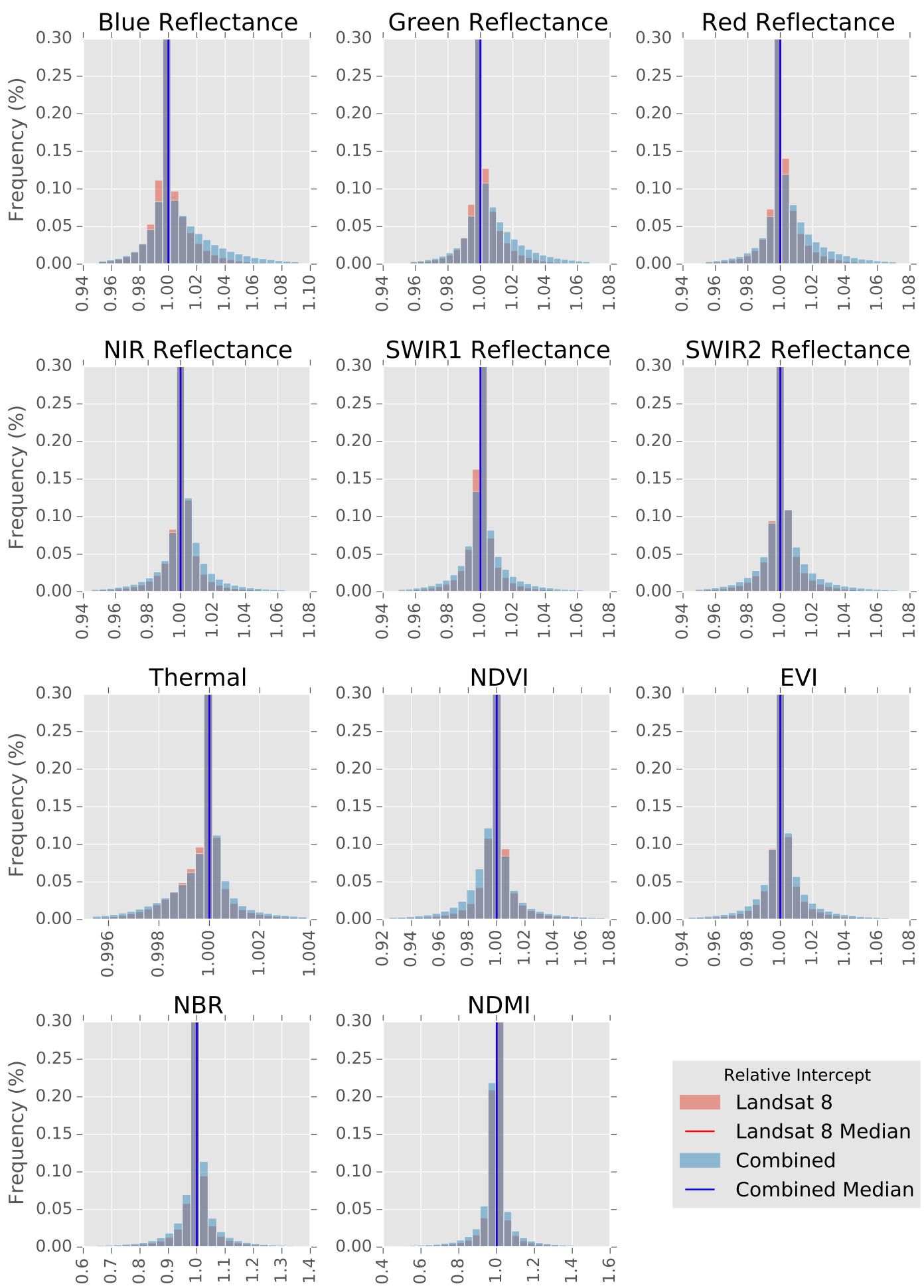

Figure 9: Normalized intercept estimates for time series models in Colorado, United States (P034R032) used to assess the influence of Landsat 8's cirrus band. Intercept estimates from time series not using Landsat 8's cirrus band in cloud masks were scaled by dividing by intercepts from time series using the cirrus band in Fmask. The $\mathrm{Y}$-axis was truncated at $30 \%$ to give better resolution to smaller frequency bins. 

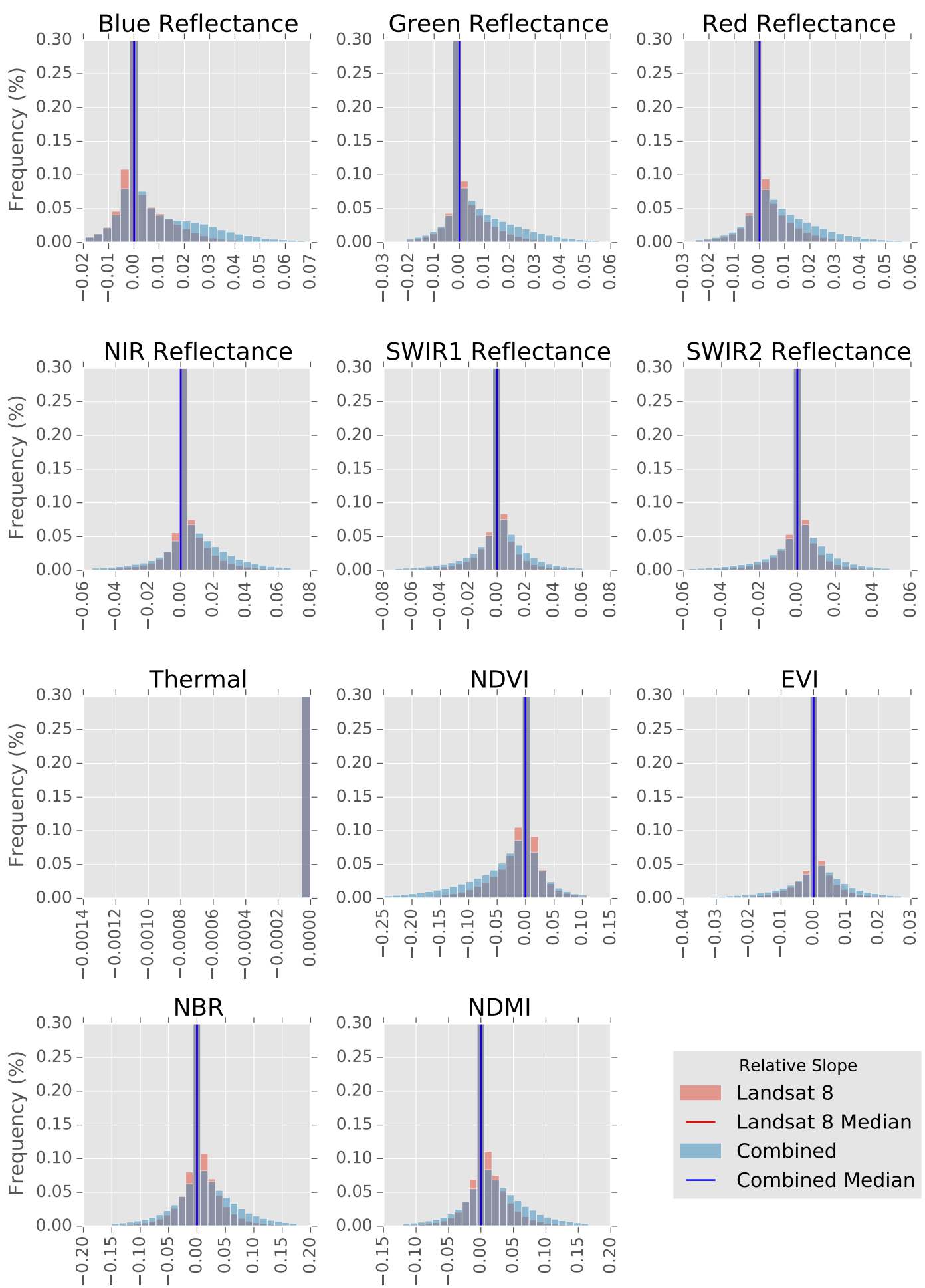

Figure 10: Normalized slope estimates for time series models in Colorado, United States (P034R032) used to assess the influence of Landsat 8's cirrus band. Slope estimates from time series not using Landsat 8's cirrus band in cloud masks were scaled by subtracting slopes from time series using the cirrus band in Fmask. The $\mathrm{Y}$-axis was truncated at $30 \%$ to give better resolution to smaller frequency bins. 

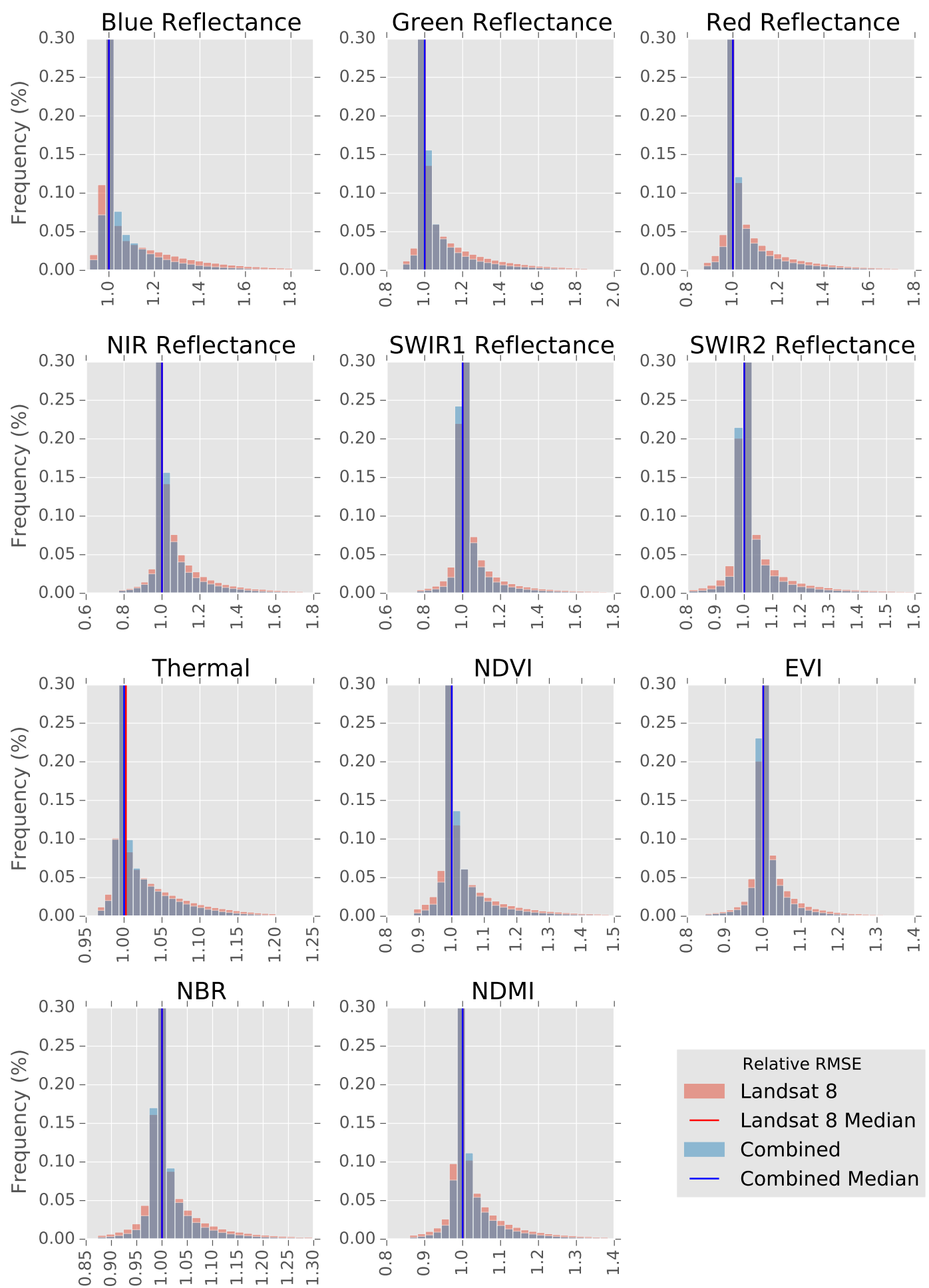

Figure 11: Normalized RMSE estimates for time series models in Colorado, United States (P034R032) used to assess the influence of Landsat 8's cirrus band. RMSE estimates from time series not using Landsat 8's cirrus band in cloud masks were scaled by dividing by RMSE from time series using the cirrus band in Fmask. The Y-axis was truncated at 30\% to give better resolution to smaller frequency bins. 
screen historical Landsat TM and ETM+ observations of cirrus clouds, already an important task, should be an increased priority to bring these time series closer to parity with Landsat 8 .

These results are reminders of previously established findings demonstrating how poor cloud and atmospheric contamination screening in time series can lead to spurious temporal trends or anomalies (Samanta et al., 2010, 2012). Improved noise screening will also improve the consistency of surface characterization by removing artificial differences in spectral properties caused by the random chance of cirrus cloud contamination. Reductions in the amount of unexplained variance in reflectance caused by previously undetectable cirrus contamination also aids change detection of surface conditions or land cover because actual changes in surface reflectance will be more distinguishable if the overall variation decreases.

\section{Conclusions}

This study of near coincident "underflight" observations and time series analysis finds consistent differences in surface reflectance between Landsat 7 ETM+ and Landsat 8 OLI Climate Data Record (CDR) surface reflectance product in the visible wavelengths. While the near infrared and shortwave infrared bands appeared brighter in Landsat 8 within the "underflight" data, differences between sensors for these bands were small and inconsistent in the time series results. Vegetation indices using the visible bands, such as the NDVI and the Tasseled Cap Greenness, tend to be brighter in Landsat 8 and have larger differences than the individual reflectance bands because the biases in the visible and near infrared bands are in the same direction these indices attempt to contrast. Despite similarly contrasting the near infrared with the red wavelengths, the Enhanced Vegetation Index (EVI) is not very different between Landsat 7 and Landsat 8. The NBR and NDMI spectral indices, which contrast the shortwave infrared bands with the near infrared band, also do not vary across sensors. While these results were generally consistent across the Landsat foot- 
prints analyzed, the relationship between Landsat 7 and Landsat 8 varied too substantially to suggest that a global relative correction method could be applied successfully. As was also suggested by Flood (2014), a local, perhaps even per-scene, relative correction should be performed to incorporate the spatial variability of the sensor differences.

Systematic differences in surface reflectance between Landsat 7 and Landsat 8 are shown to have perilous consequences for inference of gradual and abrupt change in land surface conditions. The extension of Landsat 7 time series with Landsat 8 data produces spurious time trends in bands or indices affected by sensor specific differences. Until Landsat 8 surface reflectance can be operationally adjusted to match surface reflectance from Landsat 7 , it is recommended to either estimate gradual changes over time using data from only one sensor, to perform relative correction manually, or to avoid affected bands and indices. The sensor specific bias in Landsat 8 data also hampers detection of abrupt changes because time series models are artificially noisier if variation between sensors is left unexplained.

This study did not address the improvements in time series analysis that are due to the resumed 8-day repeat cycle possible with two Landsat spacecraft in operation. Given that much of Landsat 7's acquisition footprint is unobserved due to the failure of the Scan Line Corrector, the launch of Landsat 8 has more than doubled the observation frequency since the failure of Landsat 5. Increasing the sampling frequency of observations helps time series models capture rapid intra-annual transitions, such as the phenological transitions in deciduous forests at the start and end of the growing season or the number of cropping cycles in one year. Near real time monitoring of land cover change is significantly improved with two sensors in orbit because information on change can be retrieved in a more timely manner. Land cover change techniques that use annual image composites can now be more selective when selecting the best available pixel. Even the actual detection of land cover change might be more accurate as higher frequency observations make it more likely to capture the land surface during or immediately after the change event. Increased observa- 
tion rates are especially useful in locations with pervasive cloud or snow cover or short growing seasons, including the incredibly important and changing tropical and boreal ecosystems.

Cirrus clouds detected by Fmask using Landsat 8's new cirrus band but not detected in Landsat 7 data are most distinct in the visible and thermal bands. Observations of cirrus clouds differ from clear land in visible wavelengths by less than $3 \%$ to $4 \%$ and show very little difference in the infrared wavelengths. An experiment comparing Landsat time series that do not use Landsat 8's cirrus band to screen cirrus clouds against time series that do remove cirrus clouds show that residual cirrus clouds create noticeable biases in the intercept, slope, and RMSE estimates of the visible bands and in NDVI. These contamination induced biases mimic vegetation dynamics of interest, including browning or stress events, which highlights the value of Landsat 8's cirrus band. Efforts to enhance existing cloud mask products by improving detection of cirrus clouds within TM and ETM+ data may be aided by the characterization of cirrus clouds possible using Landsat 8 observations and would be a valuable addition. Inconsistencies in surface reflectance between Landsat 7 and Landsat 8 observed in the Landsat 8 underflight dataset and in four Landsat scenes are due to a combination of three or more factors including physical changes to the spectral characteristics of Landsat 8, differences in relative calibration of sensor detectors, and differences in atmospheric correction ancillary datasets and methodology. This study did not seek to quantify the relative contribution of each factor to the differences observed, but instead focused on quantifying the observed effects and tried to offer practical advice for incorporating Landsat 8 information into existing time series methodologies. Image normalization procedures are recommended to equate the surface reflectance from Landsat 8 to Landsat 7, especially in the visible bands. The difference between sensors might also be modeled as a simple offset in reflectance which could be accomplished as an addition to a time series model specification. It is important to note that the Landsat CDR surface reflectance results described within are subject to change with alterations to sensor calibration or algorithm performance, but 
the techniques used and the lessons learned should be applicable when trying to extend the Landsat time series with observations from the upcoming Sentinel-2 satellite.

\section{Acknowledgements}

We are grateful to the support provided by the USGS Landsat Science Team Program for Better Use of the Landsat Temporal Domain: Monitoring Land Cover Type, Condition and Change (grand number G12PC00070) and to the support of NASA for Toward a Robust REDD+ Carbon Monitoring System of Deforestation and Forest Degradation (grant number WHRC-JG0866-01). We are also thankful for the careful and insightful comments made by three anonymous reviewers that helped improve this manuscript. Landsat Surface Reflectance and Landsat Spectral Indices products courtesy of the U.S. Geological Survey Earth Resources Observation and Science Center. We also thank the developers of software within the scientific Python community which helped enable our work, including the authors of SciPy (Jones et al., 2001-), NumPy (van der Walt et al. 2011), and matplotlib (Hunter, 2007).

\section{References}

Asner, G. P., Knapp, D. E., Balaji, A., Paez-Acosta, G., 2009. Automated mapping of tropical deforestation and forest degradation: Claslite. Journal of Applied Remote Sensing 3 (1), 033543-033543-24.

URL http://dx.doi .org/10.1117/1.3223675

Brooks, E., Wynne, R., Thomas, V., Blinn, C., Coulston, J., June 2014. On-thefly massively multitemporal change detection using statistical quality control charts and landsat data. IEEE Transactions on Geoscience and Remote Sensing 52 (6), 3316-3332.

Canty, M. J., Nielsen, A. A., Schmidt, M., 2004. Automatic radiometric normalization of multitemporal satellite imagery. Remote Sensing of Environment 
91 (34), $441-451$.

a URL http://www.sciencedirect.com/science/article/pii/ S0034425704001208

Crist, E. P., 1985. A tm tasseled cap equivalent transformation for reflectance factor data. Remote Sensing of Environment 17 (3), 301 - 306.

Flood, N., 2014. Continuity of Reflectance Data between Landsat-7 ETM+ and Landsat-8 OLI, for Both Top-of-Atmosphere and Surface Reflectance: A Study in the Australian Landscape. Remote Sensing 6 (9), 7952-7970.

URL http://www .mdpi . com/2072-4292/6/9/7952/

Flood, N., Danaher, T., Gill, T., Gillingham, S., 2013. An operational scheme for deriving standardised surface reflectance from Landsat TM/ETM+ and SPOT HRG imagery for eastern Australia. Remote Sensing 5 (1), 83-109.

Gao, B.-c., Goetz, A. F. H., Wiscombe, W. J., 1993. Cirrus cloud detection from airborne imaging spectrometer data using the 1.38 micron water vapor band. Geophysical Research Letters 20 (4), 301-304.

Gao, B.-C., Kaufman, Y. J., 1995. Selection of the 1.375-um modis channel for remote sensing of cirrus clouds and stratospheric aerosols from space. Journal of the atmospheric sciences 52 (23), 4231-4237.

Gao, B.-C., Kaufman, Y. J., Han, W., Wiscombe, W. J., 1998. Corection of thin cirrus path radiances in the $0.41 .0 \mathrm{~m}$ spectral region using the sensitive 1.375 m cirrus detecting channel. Journal of Geophysical Research: Atmospheres 103 (D24), 32169-32176. URL http://dx.doi.org/10.1029/98JD02006

Gao, B.-C., Li, R.-R., 2000. Quantitative improvement in the estimates of ndvi values from remotely sensed data by correcting thin cirrus scattering effects. Remote Sensing of Environment 74 (3), $494-502$. 
http://www.sciencedirect.com/science/article/pii/ S0034425700001413

Griffiths, P., Kuemmerle, T., Kennedy, R. E., Abrudan, I. V., Knorn, J., Hostert, P., 2012. Using annual time-series of Landsat images to assess the effects of forest restitution in post-socialist Romania. Remote Sensing of Environment 118, 199-214.

Hansen, M. C., Egorov, a., Potapov, P. V., Stehman, S. V., Tyukavina, A., Turubanova, S. a., Roy, D. P., Goetz, S. J., Loveland, T. R., Ju, J., Kommareddy, A., Kovalskyy, V., Forsyth, C., Bents, T., Jan. 2014. Monitoring conterminous United States (CONUS) land cover change with Web-Enabled Landsat Data (WELD). Remote Sensing of Environment 140, 466-484.

URL http://linkinghub.elsevier.com/retrieve/pii/ S0034425713002721

Hansen, M. C., Potapov, P. V., Moore, R., Hancher, M., Turubanova, S. a., Tyukavina, A., Thau, D., Stehman, S. V., Goetz, S. J., Loveland, T. R., Kommareddy, a., Egorov, A., Chini, L., Justice, C. O., Townshend, J. R. G., Nov. 2013. High-resolution global maps of 21st-century forest cover change. Science (New York, N.Y.) 342 (6160), 850-3.

URL http://www.ncbi.nlm.nih.gov/pubmed/24233722

Homer, C. G., Dewitz, J. A., Yang, L., Jin, S., Danielson, P., Xian, G., Coulston, J., Herold, N. D., Wickham, J. D., Megown, K., 2015. Completion of the 2011 National Land Cover Database for the conterminous United StatesRepresenting a decade of land cover change information. Photogrammetric Engineering and Remote Sensing 81 (5), 345-354.

Huang, C., Goward, S. N., Masek, J. G., Thomas, N., Zhu, Z., Vogelmann, J. E., Jan. 2010. An automated approach for reconstructing recent forest disturbance history using dense Landsat time series stacks. Remote Sensing of Environment 114 (1), 183-198. 
URL

http://linkinghub.elsevier.com/retrieve/pii/ S0034425709002685http://dx.doi.org/10.1016/j.rse.2009.08.017

Huang, C., Wylie, B., Yang, L., Homer, C., Zylstra, G., 2002. Derivation of a tasselled cap transformation based on Landsat 7 at-satellite reflectance. International Journal of Remote Sensing 23 (8), 1741-1748.

Huete, A., Didan, K., Miura, T., Rodriguez, E. P., Gao, X., Ferreira, L. G., 2002. Overview of the radiometric and biophysical performance of the MODIS vegetation indices. Remote Sensing of Environment 83 (1-2), 195-213.

Hunter, J. D., 2007. Matplotlib: A 2d graphics environment. Computing In Science \& Engineering 9 (3), 90-95.

Irons, J. R., Dwyer, J. L., Barsi, J. a., 2012. The next Landsat satellite: The Landsat Data Continuity Mission. Remote Sensing of Environment 122, 1121.

URL http://dx.doi.org/10.1016/j.rse.2011.08.026

Jones, E., Oliphant, T., Peterson, P., et al., 2001-. SciPy: Open source scientific tools for Python. [Online; accessed 2015-12-10]. URL http://www.scipy.org/

Kaufman, Y., Wald, A., Remer, L., Gao, B.-C., Li, R.-R., Flynn, L., Sep 1997. The MODIS $2.1 \mu \mathrm{m}$ channel-correlation with visible reflectance for use in remote sensing of aerosol. IEEE Transactions on Geoscience and Remote Sensing 35 (5), 1286-1298.

Kauth, R. J., Thomas, G. S., 1976. The tasselled cap - A graphic description of the spectral-temporal development of agricultural crops as seen by Landsat. In: 2nd International Symposium on Machine Processing of Remotely Sensed Data. pp. 4B-41-4B-51.

Kennedy, R. E., Andréfouët, S., Cohen, W. B., Gómez, C., Griffiths, P., Hais, M., Healey, S. P., Helmer, E. H., Hostert, P., Lyons, M. B., Meigs, G. W., 
Pflugmacher, D., Phinn, S. R., Powell, S. L., Scarth, P., Sen, S., Schroeder, T. a., Schneider, A., Sonnenschein, R., Vogelmann, J. E., Wulder, M. A., Zhu, Z., Jun. 2014. Bringing an ecological view of change to Landsat-based remote sensing. Frontiers in Ecology and the Environment, 140702105016007.

URL http://www.esajournals.org/doi/abs/10.1890/130066

Kennedy, R. E., Cohen, W. B., Schroeder, T. a., Oct. 2007. Trajectory-based change detection for automated characterization of forest disturbance dynamics. Remote Sensing of Environment 110 (3), 370-386.

URL

http://linkinghub.elsevier.com/retrieve/pii/ S0034425707001216

Kennedy, R. E., Yang, Z., Cohen, W. B., Dec. 2010. Detecting trends in forest disturbance and recovery using yearly Landsat time series: 1. LandTrendr Temporal segmentation algorithms. Remote Sensing of Environment 114 (12), $2897-2910$.

URL http://linkinghub.elsevier.com/retrieve/pii/ S0034425710002245

Kennedy, R. E., Yang, Z., Cohen, W. B., Pfaff, E., Braaten, J., Nelson, P., Jul. 2012. Spatial and temporal patterns of forest disturbance and regrowth within the area of the Northwest Forest Plan. Remote Sensing of Environment 122, 117-133.

URL http://linkinghub.elsevier.com/retrieve/pii/ S0034425712000417http://dx.doi.org/10.1016/j.rse.2011.09.024

Key, C. H., Benson, N. C., 2005. Landscape assessment: remote sensing of severity, the normalized burn ratio and ground measure of severity, the composite burn index. FIREMON: Fire effects monitoring and inventory system Ogden, Utah: USDA Forest Service, Rocky Mountain Res. Station, 1-55.

Kim, D.-H., Sexton, J. O., Noojipady, P., Huang, C., Anand, A., Channan, S., Feng, M., Townshend, J. R., 2014. Global, landsat-based forest-cover change from 1990 to 2000. Remote Sensing of Environment 155, 178 - 193. 
http://www.sciencedirect.com/science/article/pii/ S0034425714003149

Knight, E., Kvaran, G., 2014. Landsat-8 Operational Land Imager Design, Characterization and Performance. Remote Sensing 6 (11), 10286-10305.

Kovalskyy, V., Roy, D., 2013. The global availability of Landsat 5 TM and Landsat 7 ETM+ land surface observations and implications for global $30 \mathrm{~m}$ Landsat data product generation. Remote Sensing of Environment 130, 280-293.

URL http://www.sciencedirect.com/science/article/pii/ S0034425712004609

Kovalskyy, V., Roy, D. P., 2015. A one year landsat 8 conterminous united states study of cirrus and non-cirrus clouds. Remote Sensing 7 (1), 564.

URL http://www .mdpi . com/2072-4292/7/1/564

Li, P., Jiang, L., Feng, Z., 2014. Cross-comparison of vegetation indices derived from landsat-7 enhanced thematic mapper plus (ETM+) and landsat-8 operational land imager (OLI) sensors. Remote Sensing 6 (1), 310-329.

Loveland, T. R., Dwyer, J. L., 2012. Landsat: Building a strong future. Remote Sensing of Environment 122 (October 2000), 22-29.

URL http://dx.doi.org/10.1016/j.rse.2011.09.022

Masek, J. G., Goward, S. N., Kennedy, R. E., Cohen, W. B., Moisen, G. G., Schleeweis, K., Huang, C., May 2013. United States Forest Disturbance Trends Observed Using Landsat Time Series. Ecosystems 16 (6), 1087-1104. URL http://link.springer.com/10.1007/s10021-013-9669-9

Masek, J. G., Vermote, E. F., Saleous, N. E., Wolfe, R., Hall, F. G., Huemmrich, K. F., Gao, F., Kutler, J., Lim, T.-k., 2006. A Landsat Surface Reflectance Dataset. IEEE Geoscience and Remote Sensing Letters 3 (1), 68-72.

Meigs, G. W., Kennedy, R. E., Cohen, W. B., Dec. 2011. A Landsat time series approach to characterize bark beetle and defoliator impacts on tree mortality 
and surface fuels in conifer forests. Remote Sensing of Environment 115 (12), $3707-3718$.

URL http://linkinghub.elsevier.com/retrieve/pii/ S0034425711003361

Melaas, E. K., Friedl, M. a., Zhu, Z., May 2013. Detecting interannual variation in deciduous broadleaf forest phenology using Landsat TM/ETM+ data. Remote Sensing of Environment 132, 176-185.

URL http://dx.doi.org/10.1016/j.rse.2013.01.011http:// linkinghub.elsevier.com/retrieve/pii/S0034425713000230

Mishra, N., Haque, M., Leigh, L., Aaron, D., Helder, D., Markham, B., 2014. Radiometric Cross Calibration of Landsat 8 Operational LandImager (OLI) and Landsat 7 Enhanced Thematic MapperPlus (ETM+). Remote Sensing 6 (12), 12619-12638.

URL http://www .mdpi .com/2072-4292/6/12/12619/

Morfitt, R., Barsi, J., Levy, R., Markham, B., Micijevic, E., Ong, L., Scaramuzza, P., Vanderwerff, K., 2015. Landsat-8 Operational Land Imager (OLI) Radiometric Performance On-Orbit. Remote Sensing 7 (2), 2208-2237.

URL http://www .mdpi.com/2072-4292/7/2/2208/

Pflugmacher, D., Cohen, W. B., Kennedy, R. E., E. Kennedy, R., Kennedy, R. E., Jul. 2012. Using Landsat-derived disturbance history (19722010) to predict current forest structure. Remote Sensing of Environment 122, $146-165$.

URL http://linkinghub.elsevier.com/retrieve/pii/ S0034425712000533

Roy, D. P., Wulder, M., Loveland, T., Woodcock, C., Allen, R., Anderson, M., Helder, D., Irons, J., Johnson, D., Kennedy, R., Scambos, T., Schaaf, C., Schott, J., Sheng, Y., Vermote, E., Belward, A., Bindschadler, R., Cohen, W., Gao, F., Hipple, J., Hostert, P., Huntington, J., Justice, C., Kilic, A., Kovalskyy, V., Lee, Z., Lymburner, L., Masek, J., McCorkel, J., Shuai, 
Y., Trezza, R., Vogelmann, J., Wynne, R., Zhu, Z., Apr. 2014. Landsat-8: Science and product vision for terrestrial global change research. Remote Sensing of Environment 145, 154-172.

4 URL http://dx.doi.org/10.1016/j.rse.2014.02.001http:// linkinghub.elsevier.com/retrieve/pii/S003442571400042X

Samanta, A., Ganguly, S., Hashimoto, H., Devadiga, S., Vermote, E., Knyazikhin, Y., Nemani, R. R., Myneni, R. B., Mar. 2010. Amazon forests did not green-up during the 2005 drought. Geophysical Research Letters 37 (5), $1-5$.

URL http://doi.wiley.com/10.1029/2009GL042154

Samanta, A., Ganguly, S., Vermote, E., Nemani, R. R., Myneni, R. B., Jun. 2012. Why Is Remote Sensing of Amazon Forest Greenness So Challenging? Earth Interactions 16 (7), 1-14.

URL http://journals . ametsoc .org/doi/abs/10.1175/2012EI440.1

Schneider, A., Sep. 2012. Monitoring land cover change in urban and peri-urban areas using dense time stacks of Landsat satellite data and a data mining approach. Remote Sensing of Environment 124, 689-704.

URL http://linkinghub.elsevier.com/retrieve/pii/ S0034425712002428

Silverman, B., 1986. Density Estimation for Statistics and Data Analysis. CRC press.

Storey, J., Choate, M., Lee, K., 2014. Landsat 8 Operational Land Imager On-Orbit Geometric Calibration and Performance. Remote Sensing 6 (11), $11127-11152$.

Sulla-Menashe, D., Friedl, M., Woodcock, C. E., 2015. Sources of bias and variability in long-term Landsat time series over Canadian boreal forests. Remote Sensing of Environment In review. 
Tibshirani, R., 1996. Regression shrinkage and selection via the lasso. Journal of the Royal Statistical Society. Series B 58 (1), 267-288.

URL http://www . jstor.org/stable/2346178

Tucker, C. J., 1979. Red and photographic infrared linear combinations for monitoring vegetation. Remote Sensing of Environment 8 (2), 127-150.

U.S. Geological Survey, 2015. PRODUCT GUIDE: Landsat Surface Reflectance products courtesy of the U.S. Geological Survey, 1-27.

van der Walt, S., Colbert, S., Varoquaux, G., March 2011. The numpy array: A structure for efficient numerical computation. Computing in Science Engineering 13 (2), 22-30.

Verbesselt, J., Zeileis, A., Herold, M., Aug. 2012. Near real-time disturbance detection using satellite image time series. Remote Sensing of Environment 123, 98-108.

URL http://dx.doi.org/10.1016/j.rse.2012.02.022

Vermote, E., 2016. Placeholder: Landsat 8 surface reflectance correction. Remote Sensing of Environment PLACEHOLDER (PLACEHOLDER), 0-0.

Vogelmann, J. E., Xian, G., Homer, C., Tolk, B., Jul. 2012. Monitoring gradual ecosystem change using Landsat time series analyses: Case studies in selected forest and rangeland ecosystems. Remote Sensing of Environment 122, 92-105.

URL http://linkinghub.elsevier.com/retrieve/pii/ S0034425712000429

Wulder, M. a., Masek, J. G., Cohen, W. B., Loveland, T. R., Woodcock, C. E., 2012. Opening the archive: How free data has enabled the science and monitoring promise of Landsat. Remote Sensing of Environment 122, 2-10.

URL http://dx.doi.org/10.1016/j.rse.2012.01.010

Yan, L., Roy, D. P., 2014. Improved time series land cover classification by missing-observation-adaptive nonlinear dimensionality reduction. Remote 
Sensing of Environment 158, 478-491.

URL http://dx.doi.org/10.1016/j.rse.2014.11.024

Zhu, Z., Fu, Y., Woodcock, C. E., Olofsson, P., Vogelmann, J. E., Holden, C., Wang, M., Dai, Shu, D., Yu, Y., 2015a. Including Land Cover Change in Greenness Trend Analysis Based on All Available Landsat 5, 7, and 8 Images: A case study from Guangzhou, China (2000-2014). Remote Sensing of Environment In review.

Zhu, Z., Wang, S., Woodcock, C. E., 2015b. Improvement and expansion of the Fmask algorithm: cloud, cloud shadow, and snow detection for Landsats 4-7, 8, and Sentinel 2 images. Remote Sensing of Environment.

URL http://dx.doi.org/10.1016/j.rse.2014.12.014

Zhu, Z., Woodcock, C. E., Mar. 2012. Object-based cloud and cloud shadow detection in Landsat imagery. Remote Sensing of Environment 118, 83-94.

URL http://dx.doi.org/10.1016/j.rse.2011.10.028

Zhu, Z., Woodcock, C. E., Mar. 2014. Continuous change detection and classification of land cover using all available Landsat data. Remote Sensing of Environment 144, 152-171.

URL http://dx.doi.org/10.1016/j.rse.2014.01.011

Zhu, Z., Woodcock, C. E., Holden, C., Yang, Z., 2015c. Generating synthetic Landsat images based on all available Landsat data: Predicting Landsat surface reflectance at any given time. Remote Sensing of Environment 162, $67-83$.

URL

http://linkinghub.elsevier.com/retrieve/pii/ S0034425715000590

Zhu, Z., Woodcock, C. E., Olofsson, P., Jul. 2012. Continuous monitoring of forest disturbance using all available Landsat imagery. Remote Sensing of Environment 122, 75-91.

URL http://linkinghub.elsevier.com/retrieve/pii/
S0034425712000387http://dx.doi.org/10.1016/j.rse.2011.10.030




\begin{tabular}{|l|c|c|c|}
\hline Band & Landsat TM $(\mu \mathrm{m})$ & Landsat ETM+ $(\mu \mathrm{m})$ & Landsat OLI $(\mu \mathrm{m})$ \\
\hline Blue & Band 1: $0.45-0.52$ & Band 1: 0.45-0.52 & Band 2: 0.45-0.51 \\
Green & Band 2: 0.52-0.60 & Band 2: 0.52-0.60 & Band 3: 0.53-0.59 \\
Red & Band 3: 0.63-0.69 & Band 3: 0.63-0.69 & Band 4: 0.64-0.67 \\
NIR & Band 4: 0.76-0.90 & Band 4: 0.77-0.90 & Band 5: 0.85-0.88 \\
SWIR1 & Band 5: $1.55-1.75$ & Band 5: 1.55-1.75 & Band 6: 1.57-1.65 \\
SWIR 2 & Band 7: 2.08-2.35 & Band 7: 2.09-2.35 & Band 7: 2.11-2.29 \\
Thermal & Band 6: 10.4-12.5 & Band 6: 10.4-12.5 & Band 10: 10.6 - 11.19 \\
\hline
\end{tabular}

Table .1: Spectral band specifications for Landsat sensors TM, ETM+, and OLI

\begin{tabular}{|c|c|c|c|}
\hline WRS-2 & Common Name & Landsat 8 & Landsat 7 \\
\hline P013R010 & $\begin{array}{l}\text { Qaasuitsup, } \\
\text { Greenland }\end{array}$ & $\begin{array}{c}\text { LC80130102013089LGN01 } \\
15: 23: 37 \mathrm{Z}\end{array}$ & $\begin{array}{c}\text { LE70130102013089EDC00 } \\
\text { 15:20:58Z }\end{array}$ \\
\hline P013R029 & $\begin{array}{l}\text { New Hampshire, } \\
\text { United States }\end{array}$ & $\begin{array}{c}\text { LC80130292013089LGN01 } \\
\text { 15:31:09Z }\end{array}$ & $\begin{array}{c}\text { LE70130292013089EDC00 } \\
15: 28: 32 Z\end{array}$ \\
\hline P029R031 & $\begin{array}{l}\text { Nebraska, United } \\
\text { States }\end{array}$ & $\begin{array}{c}\text { LC80290312013089LGN01 } \\
17: 10: 31 \mathrm{Z}\end{array}$ & $\begin{array}{c}\text { LE70290312013089EDC00 } \\
\text { 17:08:13Z }\end{array}$ \\
\hline P102R076 & $\begin{array}{c}\text { Northern Territory, } \\
\text { Australia }\end{array}$ & $\begin{array}{c}\text { LC81020762013089LGN01 } \\
\text { 01:02:39Z }\end{array}$ & $\begin{array}{c}\text { LE71020762013089ASA00 } \\
\text { 00:57:18Z }\end{array}$ \\
\hline P134R042 & $\begin{array}{c}\text { Arunachal } \\
\text { Pradesh, India }\end{array}$ & $\begin{array}{c}\text { LC81340422013089LGN01 } \\
\text { 04:06:18Z }\end{array}$ & $\begin{array}{c}\text { LE71340422013089EDC00 } \\
\text { 04:01:31Z }\end{array}$ \\
\hline P134R052 & $\begin{array}{l}\text { Andaman and } \\
\text { Nicobar Islands, } \\
\text { India }\end{array}$ & $\begin{array}{c}\text { LC81340522013089LGN01 } \\
\text { 04:10:16Z }\end{array}$ & $\begin{array}{c}\text { LE71340522013089EDC00 } \\
\text { 04:05:30Z }\end{array}$ \\
\hline P150R042 & Rajasthan, India & $\begin{array}{c}\text { LE71500422013089PFS00 } \\
05: 44: 52 \mathrm{Z}\end{array}$ & $\begin{array}{c}\text { LC81500422013089LGN01 } \\
05: 40: 24 Z\end{array}$ \\
\hline P198R047 & Tombouctou, Mali & $\begin{array}{c}\text { LE71980472013089ASN00 } \\
\text { 10:42:34Z }\end{array}$ & $\begin{array}{c}\text { LC81980472013089LGN01 } \\
\text { 10:39:03Z }\end{array}$ \\
\hline P230R084 & $\begin{array}{l}\text { Mendoza, } \\
\text { Argentina }\end{array}$ & $\begin{array}{c}\text { LE72300842013089CUB00 } \\
14: 14: 24 \mathrm{Z}\end{array}$ & $\begin{array}{c}\text { LC82300842013089LGN01 } \\
14: 11: 34 Z\end{array}$ \\
\hline P230R094 & $\begin{array}{c}\text { Santa Cruz, } \\
\text { Argentina }\end{array}$ & $\begin{array}{c}\text { LE72300942013089EDC00 } \\
14: 18: 23 Z\end{array}$ & $\begin{array}{c}\text { LC82300942013089LGN01 } \\
14: 15: 34 Z\end{array}$ \\
\hline
\end{tabular}

Table .2: Scene center acquisition time for underflight data 


\begin{tabular}{|l|c|c|c|c|}
\hline WRS-2 & Common Name & Landsat 7 & Landsat 8 & Total \\
\hline P016R041 & Florida, United States & 144 & 39 & 183 \\
P023R037 & Mississippi, United States & 128 & 38 & 166 \\
P034R032 & Colorado, United States & 153 & 36 & 189 \\
P043R034 & California, United States & 139 & 38 & 177 \\
\hline
\end{tabular}

Table .3: Number of images by sensor in time series datasets 